\title{
EL FONDO DE UTILIDADES TRIBUTABLES (FUT): ELEMENTOS PARA LA DISCUSIÓN*
}

\author{
Rodrigo Cerda \\ Pontificia Universidad Católica de Chile
}

Francisco Parro

Universidad Adolfo Ibáñez

\author{
Juan Luis Correa
}

Universidad Andrés Bello

José Domingo Peñafiel

Avendaño y Merino Abogados

\begin{abstract}
Resumen: En este trabajo se analiza el Fondo de Utilidades Tributables (FUT) desde tres perspectivas diferentes. Primero, se estudia el contexto histórico en que surgió el FUT, los objetivos específicos para los cuales fue creado y las principales particularidades del régimen tributario que existió previamente a su implementación. Luego se describe la forma en que ha operado el FUT en la práctica y sus principales características. Y finalmente se analizan, desde el punto
\end{abstract}

Rodrigo Cerda. Economista PUC. Ph.D. en economía, Universidad de Chicago. Director alterno de Clapes UC. Email: rodcerdan@gmail.com.

Juan Luis Correa. Economista UGM. Ph.D. en economía, Universidad de Southampton. Director de Investigación de la Facultad de Economía y Negocios de la Universidad Andrés Bello. Email: jlcorrea_allamand@yahoo.com.

Francisco Parro. Economista PUC. Ph.D. en economía, Universidad de Chicago. Profesor de la Escuela de Negocios de la Universidad Adolfo Ibáñez. Email: fjparrog@gmail.com.

José Domingo Peñafiel. Abogado de la Pontificia Universidad Católica de Chile. Trabaja en Avendaño y Merino Abogados. Email: jdpenafiel@gmail.com.

* Este artículo se elaboró en medio de la discusión sobre el proyecto de reforma tributaria que propuso el Gobierno en el primer semestre de 2014. Se publica en conocimiento del riesgo de que algunas de sus expresiones podrían quedar descontextualizadas al momento de su publicación. Los autores agradecen a Bernardita Bulnes y Raúl Morales por su valiosa colaboración en la elaboración de este trabajo. 
de vista económico, los incentivos que ha provisto el FUT para la reinversión de utilidades. El análisis busca mostrar cómo el FUT ha constituido una herramienta efectiva de incentivo a la inversión y el ahorro dentro de las empresas. Adicionalmente, se revisó el debate creado en torno al tema, así como las principales propuestas que han emergido en la literatura para mejorar aspectos específicos del tratamiento al impuesto a la renta.

Palabras Clave: Impuestos, inversión, sistema tributario, fondo de utilidades tributables.

RECIBIDO: abril 2014; ACEPTADO: julio 2014.

\title{
THE TAXABLE PROFITS FUND (TPF): ELEMENTS FOR DISCUSSION
}

\begin{abstract}
This paper analyzes the Taxable Profits Fund (TPF) from three different perspectives. First, it studies the historical context in which the TPF emerged, the specific objectives for which it was created and the main features of the tax regime that had existed prior to its implementation. Second, it describes in detail how the TPF has operated in practice and its main features. Third, it analyzes, from an economic standpoint, the incentives that the TPF offers for a reinvestment of profits. The analysis reveals that the TPF has been an effective tool that encourages companies to invest and save. The article additionally discusses the debate on the subject and the main proposals that have emerged in literature to improve specific aspects of income taxation in Chile.
\end{abstract}

Keywords: Taxes, investment, tax system, taxable profits fund.

RECEIVED: April 2014; ACCEPTED: July 2014.

\section{INTRODUCCIÓN}

E 1 sistema tributario vigente hasta el 31 de diciembre de 1983 era - radicalmente distinto al que existió a partir de entonces. Hasta el último día de 1983, las rentas se afectaban con impuestos, incluyendo aquellas que involucraban a los propietarios, cuando eran devengadas por la empresa, independientemente de su distribución, reparto o remesa a los contribuyentes finales. Además, el sistema tributario no estaba integrado, es decir, no consideraba el pago del impuesto corporativo (impuesto de primera categoría) como un anticipo de los impuestos que debían pagar los socios de una empresa como contribuyentes del global complementario o adicional. 
Con la publicación de la Ley N. ${ }^{\circ} 18.293$, del 31 de enero de 1984, se dispuso, a contar del año calendario 1984, una verdadera revolución en cuanto a la forma de tributación de las rentas empresariales. Esa revolución estuvo motivada por una deprimida economía y la necesidad urgente de inyectar estímulos a la inversión y la creación de empleo. Bajo el nuevo sistema —el que ha sido objeto de diversos ajustes y correcciones a lo largo de su vigencia- se instauró el principio de tributación de los propietarios de las empresas sobre la base de la renta percibida, lo que significa, en términos sencillos, que mientras las utilidades no fueran retiradas y se mantuvieran reinvertidas en la empresa no se afectarían con los impuestos personales (global complementario o adicional, según el domicilio o residencia del contribuyente) ${ }^{1}$. Para aplicar y controlar este nuevo sistema de tributación en base a retiros — con sus respectivas etapas y cuidando que las rentas distribuidas o remesadas paguen el impuesto que las grava en el momento en que son percibidas por los propietarios de las empresas-, se crea el Fondo de Utilidades Tributables (FUT). Además, el nuevo régimen tributario pasó a ser un sistema integrado, en el que el pago del impuesto de primera categoría se considera un anticipo del pago de los impuestos finales (global complementario o adicional) por parte de los socios de una empresa.

Este trabajo analiza el sistema tributario que comenzó a operar a contar del primero de enero de 1984, con la Ley N. ${ }^{\circ} 18.293$, desde tres dimensiones diferentes. Primero, estudiamos las principales características del sistema tributario que operó antes de 1984, así como las razones que generaron la necesidad de un cambio en el régimen tributario y la creación del FUT. Segundo, realizamos una detallada descripción de la forma en que ha operado el FUT y de sus principales diferencias con el sistema tributario anterior y las más importantes modificaciones que ha experimentado desde su creación. Y tercero, analizamos desde el punto de vista económico los incentivos que ha provisto el FUT para la reinversión de utilidades.

${ }^{1}$ De acuerdo con la definición que contiene el artículo $2^{\circ}$ de la "Ley sobre impuesto a la renta", renta devengada es "aquella sobre la cual se tiene un título o derecho, independientemente de su actual exigibilidad y que constituye un crédito para su titular", mientras que renta percibida es "aquella que ha ingresado materialmente al patrimonio de una persona". Agrega la disposición que una renta devengada se entiende igualmente percibida "desde que la obligación se cumple por algún modo de extinguir distinto al pago". Como se advierte, esta clasificación de la renta atiende al momento en que se aplica el impuesto. 
Nuestro análisis busca mostrar que el FUT constituyó una herramienta efectiva para promover el ahorro e inversión de la economía. Identificamos dos mecanismos principales a través de los cuales el sistema tributario incentivó la reinversión de utilidades.

Un primer elemento de incentivo a la inversión se origina en las restricciones de acceso al mercado de capitales que pudiesen enfrentar algunas empresas. Aquellas que necesitan financiar proyectos rentables de inversión pero que no cuentan con fuentes externas de financiamiento deben descansar en sus fuentes internas de financiamiento, es decir, en el flujo de utilidades que quedan después del pago de impuestos. Un sistema tributario no integrado y cuya tributación es en base a la renta devengada genera una doble tributación de las utilidades: con el impuesto de primera categoría y los impuestos finales (global complementario o adicional). Éstas eran precisamente las principales características del sistema tributario vigente hasta el 31 de diciembre de 1983. Por el contrario, bajo un sistema tributario como el que comenzó a regir con la publicación de la Ley N. ${ }^{\circ}$ 18.293, mientras las utilidades no sean retiradas, no se afectan con los impuestos personales (global complementario o adicional, según el domicilio o residencia del contribuyente). Por ende, una tributación sobre la base de la renta percibida incrementa los fondos internos disponibles para la inversión en proyectos rentables y, con esto, las posibilidades de inversión respecto de un régimen en base a renta devengada.

Si un sistema tributario con base a renta devengada mantuviera la integración de los impuestos como principio tributario, el incentivo a la inversión anteriormente descrito sólo sería relevante para empresas que generan flujos de utilidades grandes. Esto porque, en dicho escenario, las empresas cuyos dueños tributan una tasa de global complementario promedio mayor a la tasa del impuesto corporativo serían las que se beneficiarían (en el sentido de un menor pago de impuestos) al reinvertir utilidades.

El segundo incentivo a la inversión del FUT existe incluso en un mundo en que las empresas no tienen restricciones de acceso al mercado de capitales. Éste se origina al resolver un problema de "injusticia tributaria" que existe en un régimen que basa la tributación en la renta devengada y que, adicionalmente, considera tasas marginales crecientes para los impuestos personales (global complementario), tal como sucedía en el sistema anterior a 1984. En este trabajo mostraremos 
cómo, bajo un régimen de tributación en base a rentas devengadas, dos sociedades que generan el mismo flujo de ingresos en valor presente pero en distintos momentos pagan un monto total de impuestos diferente. A este hecho le llamamos "injusticia tributaria" o inequidad horizontal en el pago de impuestos. A su vez, mostraremos que un régimen de tributación en base a la renta percibida permite que propietarios de sociedades que generan flujos inestables de utilidades suavicen el pago del global complementario en el tiempo, lo cual minimiza el pago total de impuestos dada la progresividad marginal de este impuesto. Esto, a su vez, genera fuertes incentivos tributarios a la reinversión de utilidades en dicho tipo de sociedades. Este efecto es independiente del grado de integración de los impuestos en el sistema tributario y sólo se origina por el hecho de poder diferir, en el tiempo, el pago del global complementario.

Finalmente, revisaremos el debate que ha existido en torno al tratamiento del impuesto a la renta y proponemos algunas directrices que podrían haber mejorado algunos aspectos del FUT, de manera de hacerlo aún más eficiente en su objetivo de promover el ahorro e la inversión dentro de las empresas. Por ejemplo, la legislación podría considerar un sistema en base a retiros para los contribuyentes del impuesto global complementario, o incluso para los del impuesto único de segunda categoría. De esta forma, el sistema tributario alcanzaría la equidad tributaria horizontal ("entre iguales, los impuestos deben ser iguales") por dos canales. Primero, al hacer que sociedades que generan el mismo flujo de utilidades en valor presente pero en distintos momentos paguen los mismos impuestos, lo cual ya se lograba con el sistema previo a la nueva reforma. Segundo, al hacer que agentes que desempeñan las mismas actividades paguen los mismos impuestos, independientemente de si producen o no sus servicios bajo el amparo de una sociedad. Es por lo tanto un FUT “ampliado” lo que verdaderamente lograría la equidad horizontal en el pago de impuestos.

Desde ya, debemos precisar que este trabajo no intenta abordar en plenitud la totalidad de los aspectos presentes en la discusión del FUT. La finalidad de este estudio es, más bien, entregar de manera rigurosa algunos elementos que sirvan como insumo para el debate respecto de potenciales modificaciones al FUT o al sistema de incentivos tributarios que finalmente se haya acordado. Dada la trascendencia que la reforma 
tributaria en curso durante este 2014 puede tener sobre la economía, creemos imprescindible la generación de este tipo de insumos.

El resto de este estudio se organiza de la siguiente manera. La sección 2 describe el sistema tributario vigente hasta el 31 de diciembre de 1983. La sección 3 analiza el sistema tributario que comenzó a regir con la publicación de la Ley N. ${ }^{\circ}$ 18.293, el 31 de enero de 1984, enfatizando las principales diferencias con el sistema antiguo. La sección 4 describe el FUT y las principales modificaciones que ha sufrido en el tiempo. La sección 5 presenta estadísticas descriptivas referentes al FUT. La sección 6 presenta un modelo simple para entender las principales diferencias entre el régimen tributario anterior a 1984 y el sistema posterior a 1984. La sección 7 presenta un análisis de los incentivos a la inversión que provee un sistema en base a renta devengada (semejante al que operó antes de 1984) y uno en base a renta percibida (sistema actual). La sección 8 revisa el debate del año 2014 en torno al tratamiento del impuesto a la renta. También, discutimos algunas propuestas que han emergido en la literatura, así como las reformas tributarias enviadas al Congreso durante el período 2010-2014. La sección 9 presenta algunas conclusiones.

\section{EL SISTEMA TRIBUTARIO ANTERIOR A 1984}

Hasta el 31 de diciembre de 1983, la legislación sobre impuesto a la renta incluía dos tributos de categoría o cedulares, un impuesto a la renta de las sociedades anónimas (llamado tasa adicional), uno a la renta de las personas naturales (impuesto global complementario) y otro a la renta de los no residentes (impuesto adicional). También existía el llamado impuesto habitacional, el cual se aplicaba sobre la renta proveniente de la agricultura, la industria, el comercio, la minería y las actividades similares.

El impuesto de primera categoría se cobraba a las sociedades anónimas y de personas, sociedades de hecho, empresas individuales y personales naturales, e incluía, en general, la renta de las empresas y toda renta diferente de aquélla derivada de servicios personales dependientes o independientes. La tasa del impuesto de primera categoría era del 10 por ciento, y al no existir el sistema integrado de tributación a la renta, no era imputable contra los impuestos personales. 
La tasa adicional era un impuesto que se aplicaba sólo a las sociedades anónimas, conjuntamente con el de primera categoría, sobre aquella parte de la renta que potencialmente podía ser distribuida a los accionistas en forma de dividendo y que, en el supuesto de ser distribuida, quedaba gravada con impuestos personales. La tasa de este impuesto era del 40 por ciento, y su razón de ser era eminentemente práctica, desde el punto de vista de la administración fiscal: al no ser posible exigir el pago del impuesto global complementario o adicional a cada uno de los accionistas de una sociedad anónima, que podían ser muchos, dada la dispersión de la propiedad y elevado número de miembros que puede existir en estas sociedades, se optó por gravar las utilidades generadas por adelantado, a nivel de la sociedad, independientemente del hecho de que fueran repartidas o no. En un esquema de tributación en base a rentas devengadas, la aplicación de la tasa adicional a la sociedad anónima no generaba mayor cuestionamiento.

Como en la práctica la tasa adicional era un adelanto de los impuestos personales, pero de cargo de la sociedad anónima, los accionistas podían rebajar de su impuesto global complementario o adicional, según el caso, una suma igual a la tasa con que se gravaron las utilidades que se les distribuyen como dividendo. Por lo tanto, en este caso, la tasa adicional y los impuestos personales sí estaban integrados.

Por su parte, el impuesto de segunda categoría, conceptualmente similar al que existe hoy, se aplicaba a las personas naturales con respecto a su renta derivada de servicios personales, e incluía las rentas provenientes del trabajo dependiente y la renta de servicios profesionales, así como de otros servicios personales independientes prestados por personas naturales o por sociedades de profesionales.

El impuesto de segunda categoría gravaba la renta del trabajo dependiente con tasas progresivas que iban desde 0 a 58 por ciento, y la renta derivada de servicios personales independientes con una tasa proporcional del 7 por ciento. Las rentas del trabajo dependiente estaban exentas del impuesto global complementario, pero, al igual como ocurre hoy, se tomaban en cuenta para la determinación de su tasa.

Finalmente, el impuesto a la renta de las personas naturales (impuesto global complementario) era pagado por las personas residentes, con respecto a su renta global, con tasas progresivas que iban desde $0 \mathrm{a}$ 58 por ciento. El impuesto a la renta de los no domiciliados o residentes 
(impuesto adicional) se aplicaba a las sucursales de las compañías extranjeras y, en general, a las personas naturales y jurídicas sin domicilio ni residencia en Chile, con una tasa del 40 por ciento.

El sistema descrito fue criticado porque gravaba la renta en forma excesiva, producía el efecto de incentivar la distribución de la renta por parte de las empresas (lo que atentaba contra la reinversión) y favorecía el financiamiento por medio de préstamos, en desmedro del financiamiento del capital accionario o de riesgo.

\section{EL SISTEMA TRIBUTARIO A CONTAR DE 1984}

Teniendo presente el duro contexto económico por el que atravesaba la economía chilena durante la primera mitad de la década de los ochenta y considerando las dificultades estructurales del sistema tributario entonces vigente, la Junta de Gobierno de la época generó un proyecto de ley que avanzara en reformas estructurales que incentivaran el ahorro y la inversión, el que sería finalmente aprobado en la Ley N. ${ }^{\circ}$ 18.293. El mensaje del proyecto de ley afirmaba que las modificaciones tendrían por objeto principal resolver el problema del bajo ahorro, readecuar la estructura financiera de las empresas y permitirles una mayor capacidad de ahorro e inversión. Debe tenerse presente que si bien la crisis financiera que afectaba al país en ese momento fue posiblemente la principal razón que motivó esta reforma tributaria, el peso de la estructura anterior y su negativo efecto en la productividad y generación de empleo quizá habrían justificado por sí mismo el tránsito hacia un sistema que incentivara el ahorro al interior de las empresas.

En su versión original, el proyecto de ley se estructuraba sobre un esquema de tributación único en base a retiros o a renta percibida, en virtud del cual, si las utilidades no eran definitivamente retiradas de las empresas, no se generaba impuesto alguno, ni aun el corporativo. De esta forma, el proyecto derogaba los siguientes impuestos: el de primera categoría, el que se aplicaba a las sociedades anónimas (tasa adicional), el de segunda categoría (sólo en lo que respecta a servicios personales independientes) y el habitacional. No obstante, mantenía vigente el impuesto de segunda categoría en cuanto a las rentas del trabajo dependiente, y el impuesto progresivo a la renta de las personas naturales. De acuerdo con el proyecto, el impuesto de primera categoría y el global 
complementario debían aplicarse sobre la renta efectivamente pagada o distribuida a la persona natural. Si la persona que recibía la renta distribuida por una empresa la reinvertía en otra, la renta reinvertida no era gravada mientras se mantuviera en la empresa receptora de la inversión. En el caso de las empresas extranjeras, la renta se gravaba una vez retirada o remesada al exterior.

Alternativamente al sistema descrito, y como gran novedad, en su versión original el proyecto de ley establecía, en su artículo $9^{\circ}$, un impuesto al consumo para las personas que no tributaran bajo la modalidad de retiros, el que era optativo para el contribuyente. En general, este gravamen al consumo consideraba como ingresos todas las cantidades percibidas por las personas en el año calendario, no sólo por concepto de beneficios o utilidades, sino que también por el valor de las enajenaciones de bienes, indemnizaciones, etcétera. De estos ingresos debían descontarse las inversiones realizadas en el mismo año por el contribuyente. La base tributable consideraba además el endeudamiento del año, el cual, naturalmente, impactaba en la inversión, y la escala de tasas y créditos era la misma que a la época del proyecto de ley se aplicaba al impuesto global complementario. El impuesto al consumo fue finalmente descartado, por lo que nunca se transformó en ley.

Con la publicación de la Ley N. ${ }^{\circ} 18.293$, del 31 de enero de 1984, se dispuso, a contar del año calendario 1984, una verdadera revolución en cuanto a la forma de tributación de las rentas generadas en las empresas. Bajo el nuevo sistema, se instauró el principio de tributación de las rentas empresariales con impuestos personales sobre la base de renta percibida, lo que implicó, como se ha explicado, que mientras las utilidades no fueran retiradas de la empresa que las generó y se mantuvieran en la misma, o fueran retiradas para ser reinvertidas en otras empresas, no se afectarían con impuestos personales (global complementario o adicional, en su caso). Las utilidades generadas por las empresas, en cambio, se afectaban con el impuesto de primera categoría al momento de su devengo, lo que determinó que este gravamen constituyera en la práctica un pago por adelantado a cuenta de los impuestos personales, el que era retenido por la empresa. Así, la introducción del sistema de tributación en base a retiros, en contraste al de la renta devengada, fue 
quizás el cambio más radical con respecto al mecanismo vigente con anterioridad a la reforma ${ }^{2}$.

En complemento con lo anterior, se estableció también el principio de la integración de los impuestos, según el cual el tributo que pagan los propietarios por las rentas generadas en las respectivas empresas es uno solo, de manera que el impuesto de primera categoría actúa como una retención a cuenta de los tributos personales, lo que constituye un adelanto de recursos para el Fisco. Dado el diseño de esta estructura, los propietarios de las empresas tienen derecho a abonar como crédito el impuesto corporativo que gravó a las mismas utilidades que son retiradas o remesadas. Este diseño de impuestos integrados tiene varias ventajas: evita los problemas de doble tributación; afecta en forma positiva

${ }^{2}$ Lo que determina en Chile el tipo de impuestos que paga un contribuyente no es la figura jurídica que éste adopta (sociedad o persona natural), sino que la actividad generadora de rentas que desarrolla, y, específicamente, si las rentas provienen del capital o del trabajo. El artículo 20 de la "Ley sobre impuesto a la renta" (antes de la reforma en curso) contiene el catálogo de rentas que se encuentran afectas con el impuesto de primera categoría. El numeral 5 de dicho artículo señala que se afectan con este impuesto "todas las rentas, cualquiera que fuera su origen, naturaleza o denominación, cuya imposición no esté establecida expresamente en otra categoría". Por lo tanto, el impuesto de primera categoría está establecido de manera residual y se aplica sobre toda renta que no esté establecida expresamente en otra categoría. Como solamente hay dos categorías de impuesto, entonces tributan con primera categoría las rentas que no se afectan con impuesto de segunda categoría. Bajo este principio, lo anterior cobra especial relevancia si se considera que algunas utilidades pueden considerarse "del capital", según el tipo de entidad que las genera y no según la naturaleza de la actividad productiva de la renta. En efecto, según lo dispuesto en el artículo $42,{ }^{\circ}{ }^{\circ} 2$, de la "Ley sobre impuesto a la renta" (que establece las rentas afectas al impuesto de segunda categoría, y particularmente, las rentas provenientes del ejercicio de profesiones liberales y profesiones lucrativas), se clasifican dentro de la segunda categoría los "ingresos provenientes del ejercicio de las profesiones liberales o de cualquiera otra profesión u ocupación lucrativa no comprendida en la primera categoría". Dado que una sociedad no puede ejercer una profesión liberal ni tampoco, por expresa disposición de la ley, realizar una ocupación lucrativa, el desarrollo de actividades que por su naturaleza corresponden a servicios personales, efectuados por sociedades, al no poder ser clasificadas en el mencionado artículo 42, n. ${ }^{\circ}$, de la "Ley sobre impuesto a la renta", necesariamente deben clasificarse en el artículo $20, n{ }^{\circ} 5$, de dicha ley, como ingresos residuales no pertenecientes a ninguna otra categoría, lo que conlleva la aplicación del impuesto de primera categoría, con todas las obligaciones anexas que ello implica, dentro de las que se cuentan el deber de llevar contabilidad completa y, consiguientemente, el registro FUT. 
especialmente a los pequeños empresarios y pequeños accionistas, y permite que en el largo plazo las rentas del trabajo y del capital paguen impuestos parecidos ${ }^{3}$.

Tal como se adelantaba en los párrafos anteriores, la forma de aplicar y controlar este nuevo sistema de tributación en base a renta percibida, con sus respectivas etapas y cuidando que las rentas retiradas o remesadas paguen el impuesto que las grava en el momento en que son percibidas se llamó el Fondo de Utilidades Tributables (FUT).

Es necesario hacer presente que de manera excepcional, y únicamente respecto del año calendario 1989, las utilidades generadas por las empresas se afectaron sólo con el impuesto de primera categoría cuando fueran retiradas o distribuidas a sus socios o accionistas. En otras palabras, en dicho período, el impuesto de primera categoría se aplicó en base a renta percibida, conjuntamente con los impuestos personales ${ }^{4}$. Esto explica que las utilidades registradas en el FUT de las empresas, correspondiente al año comercial 1989, no tengan asociado crédito por impuesto de primera categoría. A contar del año 1990, con la Ley N. ${ }^{\circ}$ 18.985, se volvió al régimen de renta devengada en lo que respecta a la aplicación del señalado impuesto.

${ }^{3}$ Adicionalmente, el Impuesto Único de Segunda Categoría, establecido en el artículo 43, n. ${ }^{\circ}$, de la "Ley sobre impuesto a la renta" se aplica a las rentas del trabajo dependiente, tales como los sueldos, pensiones (excepto las de fuente extranjera) y rentas accesorias o complementarias a las ya mencionadas. Se trata de un tributo progresivo que se determina mediante una escala de tasas, empezando por un primer tramo exento hasta un último tramo con una tasa marginal de 40 por ciento. Su cálculo se realiza sobre el salario y/o remuneraciones del trabajo, deduciendo previamente los pagos por concepto de seguridad social y de salud. Este impuesto debe ser retenido y enterado mensualmente en arcas fiscales por el respectivo empleador o pagador de la renta. Por su parte, los ingresos que perciben las personas provenientes del ejercicio de una actividad profesional o de cualquier otra profesión $\mathrm{u}$ ocupación lucrativa en forma independiente, tal como lo disponen los artículos $42 \mathrm{n}^{\circ}$. 2 y 43 n. 2 de la "Ley sobre impuesto a la renta", no se encuentran gravados con este impuesto único, sino que con el Global Complementario o el Adicional. Sin embargo, estas personas están sujetas a una retención o pago provisional del 10 por ciento sobre la renta bruta al momento de percibirla. Esta retención o pago provisional son utilizados por el contribuyente rebajándolos como crédito de los impuestos personales antes indicados, pudiendo solicitar la devolución del excedente que resulte de la liquidación anual practicada, en los casos que correspondan de acuerdo con la misma ley.

${ }^{4}$ Esta modificación fue introducida por la Ley N. ${ }^{0} 18.775$, publicada en el Diario Oficial el 14 de enero de 1989. 


\section{EL FONDO DE UTILIDADES TRIBUTABLES}

Para efectos de la aplicación práctica de este nuevo sistema de tributación, se hizo necesario establecer un control para la determinación y registro de las utilidades acumuladas en la empresa que se encontraban pendientes de reparto o distribución a los propietarios, para efectos de su imputación y de los créditos asociados a las mismas utilidades. Por esta razón, y teniendo presente que la Ley N. ${ }^{\circ} 18.293$ no contempló en ninguna de sus normas la obligatoriedad de llevar un registro para este tipo de rentas (aunque sí quedó constancia de la necesidad de dicho registro en el mensaje de la ley), el Servicio de Impuestos Internos (SII), mediante la resolución exenta 891, de 1985, creó el "Registro de renta líquida imponible de primera categoría y de utilidades tributables", estableciendo para los contribuyentes de la primera categoría que determinen sus rentas efectivas demostradas mediante contabilidad completa y balance general la obligatoriedad de llevar este libro de registro especial.

Posteriormente, en la Ley N. ${ }^{\circ} 18.985$, publicada en el Diario Oficial el 28 de junio de 1990, se reconoció expresamente la existencia del FUT, cuya reglamentación fue efectuada por el SII en la resolución exenta 2.154, de 1991. Otras modificaciones que contiene esta ley con respecto al FUT son analizadas más adelante en esta misma sección.

En lo que respecta a las anotaciones que debían efectuarse en el FUT, se encontraban, entre otras, la renta líquida imponible de primera categoría, las utilidades generadas por terceros (cuyo origen proviene de participaciones sociales, dividendos percibidos de sociedades anónimas o retiros de utilidades tributarias efectuados en otras empresas que han sido recibidos en calidad de reinversión), la diferencia entre la depreciación acelerada y la depreciación normal ${ }^{5}, \mathrm{y}$ los ingresos que no se reputan renta de acuerdo con la ley. También se contabilizan las rentas exentas del impuesto global complementario o adicional y las afectas al impuesto de primera categoría en carácter de único a la renta.

${ }^{5}$ Establecida en el inciso tercero, del N. ${ }^{\circ}$ 5, del artículo 31, de la "Ley sobre impuesto a la renta", incorporado por la Ley N. ${ }^{\circ} 19.738$. 
En el caso de las sociedades de personas y contribuyentes del artículo $58, \mathrm{n} .{ }^{\circ} 1$, de la "Ley sobre impuesto a la renta", el registro FUT permitía establecer la situación tributaria de las cantidades que se retiran, así como llevar un control de la tributación con impuestos finales de las utilidades que, por mantenerse en la empresa, no han sido objeto de tributación por parte de los propietarios. También se controlaba la antigüedad y origen de las utilidades para los efectos de establecer los créditos asociados a los retiros y distribuciones por concepto de impuesto de primera categoría.

Tratándose de las sociedades anónimas, el FUT tenía por objetivo determinar los créditos que benefician a las utilidades que se distribuyen, pero no definir la situación tributaria de éstas, ya que en el caso de estas sociedades toda cantidad que se distribuya tributa con el impuesto global complementario o adicional, salvo que se impute a una renta que forme parte del fondo de utilidades no tributables (FUNT).

Dicho lo anterior, podemos entonces concluir que el FUT representaba todas aquellas utilidades que constituyen flujos tributarios efectivos que son susceptibles de ser retiradas por los dueños de las empresas, pero que éstos han decidido mantenerlas invertidas en ellas (ya sea no retirándolas o reinvirtiéndolas en otras sociedades), postergando su tributación con los impuestos personales. Queda, entonces, de manifiesto, que el principal objetivo que tuvo el legislador al instaurar este sistema tributario fue el incentivo al ahorro y a la inversión (Catrilef 2010). Así, por lo demás, consta en las actas de las comisiones legislativas de la Ley N. ${ }^{\circ} 18.293^{7}$.

Además de los casos señalados precedentemente, a lo largo de los años el FUT experimentó una serie de mejoras, las que han tenido por finalidad corregir ciertas situaciones de abuso e introducir perfeccionamientos al sistema. Entre estas modificaciones, las que merecen mención especial por su relevancia son:

${ }^{6}$ El artículo 58, n. ${ }^{\circ}$ 1, de la "Ley sobre impuesto a la renta", grava con el impuesto adicional a las personas naturales sin domicilio ni residencia en Chile y a las sociedades o personas jurídicas constituidas fuera del país, que tengan cualquier clase de establecimiento permanente en Chile, por el total de las rentas remesadas al exterior o retiradas que sean atribuibles a éstos.

${ }^{7}$ En efecto, el mensaje de esta ley señalaba al respecto: “[...] las modificaciones que se proponen a la 'Ley sobre impuesto a la renta' tienen por finalidad principal resolver el problema del bajo ahorro, readecuando la estructura financiera de las empresas, permitiéndoles una mayor capacidad de ahorro e inversión". 
1) La Ley N. ${ }^{\circ} 18.489$, publicada en el Diario Oficial el 4 de enero de 1986, cuyo objetivo fue precisar algunas situaciones que no quedaron suficientemente definidas y coordinadas con ocasión de la reforma introducida a la "Ley sobre impuesto a la renta" mediante la Ley N. ${ }^{\circ}$ 18.293. Dentro de las modificaciones incorporadas por esta ley se cuentan el llamado "FUT devengado", el cual permitió que las sociedades de personas pudieran imputar los retiros en exceso del FUT al mismo fondo de otras empresas en las que éstas tuvieran participación con prescindencia del resultado tributario del ejercicio para efectos de la tributación que afecta a los retiros presuntos del antiguo artículo 21 de la "Ley sobre impuesto a la renta".

2) La Ley N. ${ }^{\circ} 18.775$, publicada en el Diario Oficial el 14 de enero de 1989, cuyo objetivo fue establecer un sistema de tributación excepcional para el año comercial 1989, que consistió, en pocas palabras, en aplicar el impuesto de primera categoría a las utilidades generadas durante dicho período sólo en la medida en que fueran retiradas o distribuidas a los propietarios de las empresas. Este sistema se mantuvo solamente para las utilidades generadas en el ejercicio 1989, siendo derogado por la Ley N. ${ }^{\circ} 18.985$, que devolvió el escenario a la situación anterior. La modificación introducida por la Ley N. ${ }^{\circ} 18.775$ en comento explica el que las utilidades generadas durante el año 1989 e incorporadas en el FUT de la empresa no hayan tenido - ni tengan - derecho a imputar el crédito de primera categoría asociado a las mismas utilidades. Cabe recordar que esta forma de tributación con el impuesto de primera categoría era la que contemplaba originalmente el proyecto de la Ley N. ${ }^{\circ} 18.293$.

3) La Ley N. ${ }^{\circ} 18.985$, publicada en el Diario Oficial el 28 de junio de 1990, es quizá la gran reforma tributaria desde el retorno de la democracia. Sin modificar de manera radical el sistema de tributación del impuesto a la renta, introdujo cambios sustanciales en lo que respecta al FUT.

Esta ley dispuso, en primer lugar, el regreso al sistema de aplicación del impuesto de primera categoría sobre renta devengada (vigente hasta 1988 y modificado transitoriamente por la Ley N. ${ }^{\circ}$ 18.775), lo que en la práctica implicó volver a gravar a las empresas con este tributo, reflejándose nuevamente en un crédito en el FUT. También, en lo que interesa, modificó la "Ley sobre impuesto a la renta" de la siguiente for- 
ma: (i) se consideraron retiradas por los propietarios, y en consecuencia gravadas con los impuestos personales aplicables en el mismo ejercicio, las utilidades generadas por empresas que no declaran sus rentas efectivas mediante contabilidad completa o que están acogidas al régimen de renta presunta; (ii) se reguló el tratamiento de los retiros en exceso de FUT efectuados desde sociedades de personas, pero manteniendo el sistema de reinversión de utilidades en otras empresas que determinen su renta efectiva según contabilidad completa, postergando los impuestos global complementario o adicional ${ }^{8}$; (iii) se reguló expresamente y más en detalle el FUT, el que, como fue señalado, hasta esa fecha sólo era reconocido a través de una circular del Servicio de Impuestos Internos; (iv) se estableció, además, un orden de imputación de los retiros, remesas o distribuciones que efectúen las empresas a sus propietarios, socios o accionistas, comenzando por las rentas tributables más antiguas, con el objetivo de evitar el retiro de cantidades correspondientes a ingresos no renta o exentas de impuesto global complementario o adicional, con el consiguiente impacto en las arcas fiscales ${ }^{9}$, y (v) se permitió a los contribuyentes del impuesto de primera categoría deducir de su renta líquida imponible, como gasto necesario, las pérdidas incurridas por el negocio o empresa durante el año comercial a que se refiere el impuesto, admitiéndose incluso la devolución del impuesto pagado por utilidades generadas en ejercicios anteriores ${ }^{10}$.

${ }^{8}$ De acuerdo con esta regulación, si en un ejercicio se efectúan retiros o remesas en una sociedad de personas en exceso del fondo de utilidades tributables, que no correspondan a cantidades no constitutivas de renta o rentas exentas de los impuestos global complementario o adicional, se considerarán los recursos como retirados en el primer ejercicio posterior en que la empresa tenga utilidades tributables, hasta por el monto de tales cantidades generadas en dicho ejercicio, entendiéndose postergada la tributación. Esta disposición se hizo cargo de un vacío legal existente con anterioridad, en virtud del cual los retiros en exceso de FUT no tributaban nunca.

${ }^{9} \mathrm{La}$ modificación incorporada al artículo 14 de la "Ley sobre impuesto a la renta" por la Ley N. ${ }^{\circ} 18.985$ dispuso que los retiros, remesas o distribuciones se imputarían, en primer término, a las rentas o utilidades afectas al impuesto global complementario o adicional, comenzando por las más antiguas y con derecho al crédito que corresponda, de acuerdo con la tasa del impuesto de primera categoría que les haya afectado. En el caso de que resultare un exceso, éste será imputado a las rentas exentas o cantidades no gravadas con dichos tributos. En consecuencia, sólo una vez agotadas las rentas tributables registradas en el FUT, las utilidades distribuidas podrán imputarse a los ingresos no constitutivos de renta o a rentas exentas de los impuestos global complementario o adicional.

${ }^{10}$ Esto es lo que se conoce como pago provisional por utilidades absorbidas. 
4) La Ley N. ${ }^{0} 19.578$, publicada en el Diario Oficial el 29 de julio de 1998, introdujo nuevas modificaciones al artículo 14 de la "Ley sobre impuesto a la renta", las que tuvieron por objetivo corregir algunas situaciones que se producían en relación con los retiros de utilidades para ser reinvertidos en otras empresas. Cabe recordar que estos retiros, desde la creación del sistema, nunca fueron afectados con impuestos.

Entre otras materias, esta ley corrigió una situación que se producía en la enajenación de acciones de pago de sociedades anónimas abiertas adquiridas con utilidades reinvertidas, las que hasta antes de esta modificación nunca pagaban el impuesto global complementario o adicional que se encontraba pendiente, regulándose asimismo el tratamiento del mayor valor obtenido en dicha enajenación y la reinversión del precio de su enajenación.

5) La Ley N. ${ }^{\circ} 19.738$, publicada en el Diario Oficial el 19 de junio de 2001, también conocida como "Ley de lucha contra la evasión", surge del compromiso expresado en el programa de Gobierno del Presidente Ricardo Lagos en cuanto a "financiar los mayores requerimientos de gastos en programas sociales y de desarrollo no mediante un aumento de impuestos sino a través de una reducción de la elusión y evasión tributaria"11. Dentro de sus principios rectores se cuentan el fortalecimiento de la fiscalización de los impuestos; la reducción de fuentes de evasión y elusión que existían en la legislación tributaria, y la modernización y fomento de una mayor eficiencia en los organismos de la administración tributaria.

Esta ley incorporó importantes modificaciones al FUT, dentro de las que se cuentan el considerar como un retiro la enajenación de acciones de sociedades anónimas cerradas adquiridas mediante una reinversión de utilidades, y la modificación a las normas sobre depreciación acelerada, en el sentido de que ésta sólo tendrá efectos en la determinación de la renta líquida imponible de las empresas, pero no en el FUT, donde se considera como gasto sólo la depreciación normal.

6) La Ley N. ${ }^{\circ} 20.630$, publicada en el Diario Oficial el 27 de septiembre de 2012, que perfecciona la legislación tributaria y financia la reforma educacional, modificó el artículo 21 de la "Ley sobre impuesto

${ }^{11}$ Mensaje Presidencial del proyecto de ley que establece normas legales para combatir la evasión tributaria, el que posteriormente se convertiría en la Ley N. ${ }^{\circ}$ 19.738 . 
a la renta", haciendo de cargo de la sociedad el impuesto-multa de tasa 35 por ciento (aplicable en general a los gastos rechazados y a los retiros presuntos), y alternativamente, en reemplazo de dicho impuesto, gravando al contribuyente del impuesto global complementario o adicional con el respectivo tributo incrementado en un monto equivalente al 10 por ciento de la partida correspondiente. Además, entre otras materias, la Ley N. ${ }^{\circ} 20.630$ igualó prácticamente en todos los aspectos el tratamiento tributario del mayor valor obtenido en la enajenación de acciones de sociedades anónimas cerradas con el de los derechos societales.

\section{ESTADÍSTICAS DESCRIPTIVAS}

En esta sección presentamos estadísticas descriptivas relativas al FUT. El gráfico 1 muestra el nivel y evolución del FUT acumulado durante el período 2004-2012. Las cifras exhibidas en el gráfico corresponden al monto del FUT a comienzos del año calendario. Vemos que entre el 2004 y el 2012, el FUT ha crecido más de 300 por ciento desde un nivel de 62.500 millones de dólares en el 2004 hasta más de 250.000 millones de dólares en el 2012. Es claro que la tasa de crecimiento no es estable en el tiempo. Particularmente notorio es el quiebre en el año 2009, reflejando posiblemente el efecto de la crisis financiera global.

Gráfico 1. FUT ACUMULADO 2004-2012

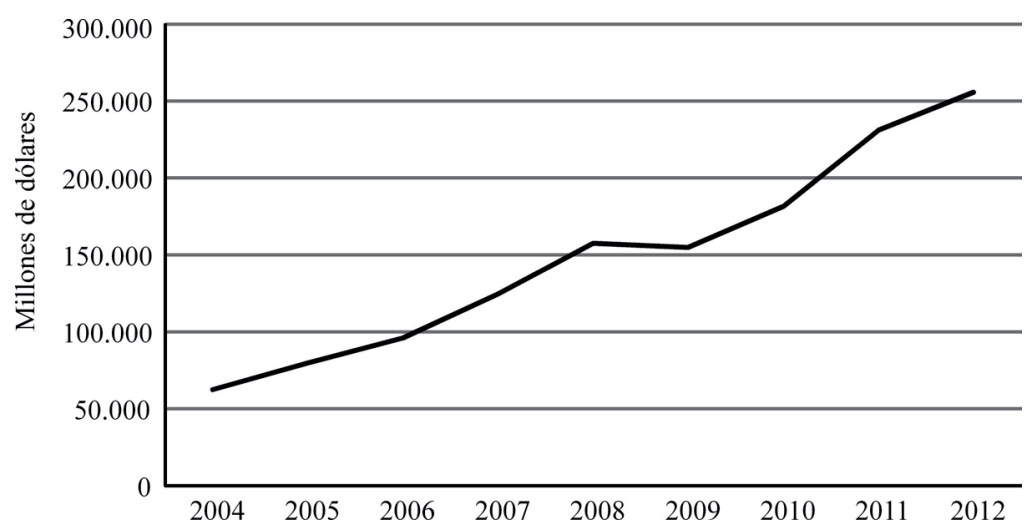

Fuente: Elaboración de los autores en base a datos del SII correspondientes a la operación renta de cada año. 
Para entender qué tipo de empresa alberga la mayor parte del FUT exhibido en el gráfico 1, clasificamos las sociedades en tres grupos de acuerdo con su nivel de renta líquida imponible (RLI) total en el período 2004-2012: pequeñas, medianas y grandes. Las sociedades pequeñas agrupan al 25 por ciento que presenta la menor RLI. Por su parte, las sociedades grandes agrupan al 25 por ciento con la mayor renta líquida imponible. El resto de las sociedades se clasificaron como medianas.

La tabla 1 muestra el porcentaje del total del FUT que se encuentra en estos tres tipos de empresas. Podemos observar que las grandes concentran la mayor parte del FUT, alcanzando en todos los períodos más del 90 por ciento del total. Por su parte, las empresas pequeñas y medianas acumulaban en conjunto alrededor del 8,5 por ciento del total en el año 2004, porcentaje que disminuyó de manera importante durante la crisis financiera, llegando a un mínimo de 5,5 por ciento en 2008. Posteriormente ha existido un leve repunte, pero sin lograr los niveles previos a la crisis.

Tabla 1. DISTRIBUCIÓN DEL FUT POR TIPO DE EMPRESAS

\begin{tabular}{cccc}
\hline Año calendario & $\begin{array}{c}\text { Pequeñas } \\
\%\end{array}$ & $\begin{array}{c}\text { Medianas } \\
\%\end{array}$ & $\begin{array}{c}\text { Grandes } \\
\%\end{array}$ \\
\hline 2004 & 1,35 & 7,16 & 91,49 \\
2005 & 1,13 & 6,37 & 92,50 \\
2006 & 1,01 & 5,91 & 93,09 \\
2007 & 0,87 & 5,13 & 93,99 \\
2008 & 0,79 & 4,71 & 94,50 \\
2009 & 0,78 & 4,74 & 94,48 \\
2010 & 0,86 & 5,20 & 93,94 \\
2011 & 0,82 & 4,99 & 94,19 \\
2012 & 0,88 & 5,29 & 93,83 \\
\hline
\end{tabular}

Fuente: Elaboración de los autores en base a datos del SIl correspondientes a la operación renta de cada año.

A continuación mostramos el retiro de utilidades ${ }^{12}$ como porcentaje del FUT acumulado y de la renta líquida imponible. No deducimos

12 Parte del retiro de utilidades considera reinversiones en otras sociedades. Sin embargo, este componente representa menos del 10 por ciento de los retiros. Adicionalmente, debido a que la reinversión en otras sociedades debe realizarse dentro de un plazo preestablecido, parte de dicha reinversión estará sujeta al global complementario al igual que los retiros realizados con fines de consumo. 
los impuestos pagados de ésta para evitar que la existencia de distintos créditos y otros tratamientos tributarios de las empresas disminuya su comparabilidad. Realizamos esto para el total de las sociedades, así como para los distintos grupos clasificados de acuerdo con su nivel de renta líquida imponible. Los gráficos 2 y 3 muestran los resultados.

Gráfico 2. RETIROS COMO PORCENTAJE DEL FUT, 2004-2012

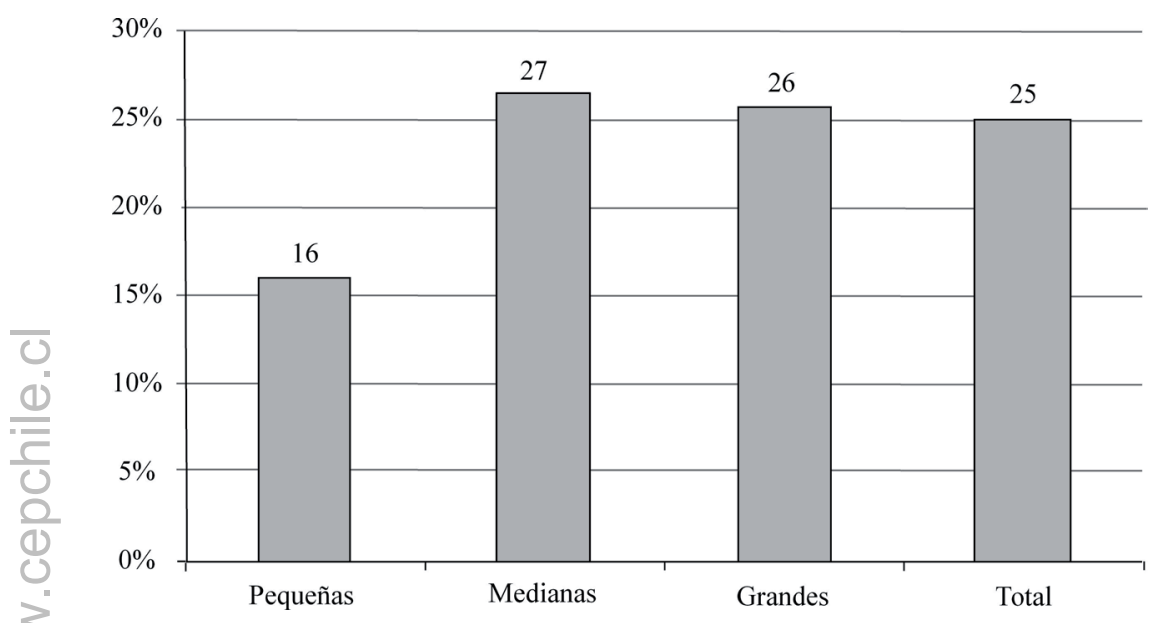

Fuente: Elaboración de los autores en base a datos del SIl correspondientes a la operación renta de cada año.

Gráfico 3. RETIROS COMO PORCENTAJE DE LA RENTA LÍQUIDA IMPONIBLE, 2004-2012

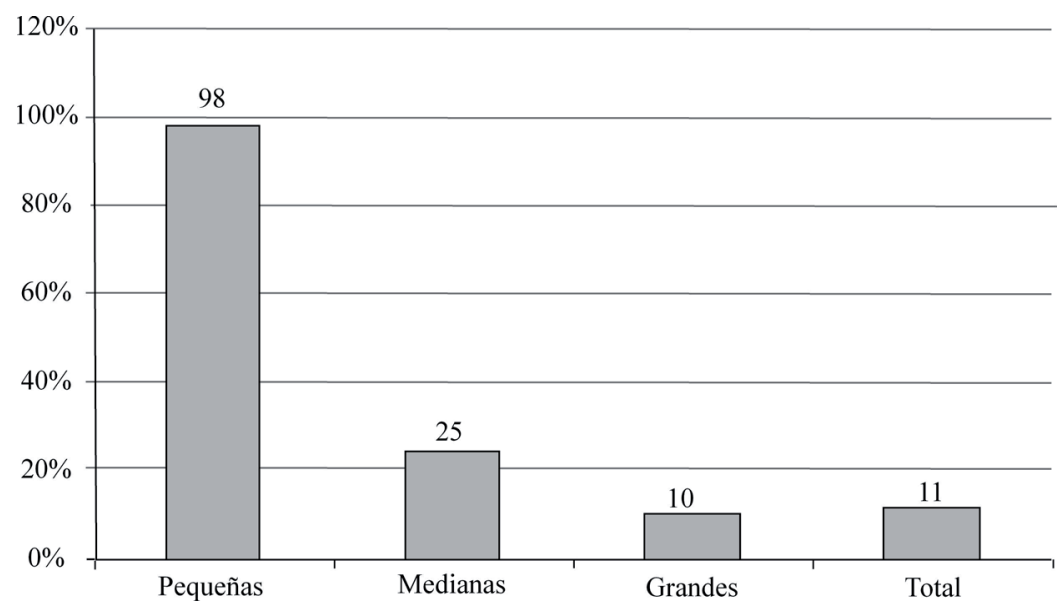

Fuente: Elaboración de los autores en base a datos del SIl correspondientes a la operación renta de cada año. 
Vemos en el gráfico 2 que las empresas retiran, en promedio, alrededor del 25 por ciento del FUT cada año, siendo este porcentaje algo menor para las sociedades más pequeñas. Debido a que los retiros se imputan al FUT en orden cronológico, esto permite concluir que la rotación de las utilidades reinvertidas es relativamente alta y que, en promedio, los incentivos de las empresas a reinvertir provocan que no se retengan durante periodos largos ( 10 o 20 años). Esto sugiere que el rol del FUT estaba más cercano a una suavización más que de la dilatación del pago de impuestos. Adicionalmente, vemos en el gráfico 3 que en el caso de sociedades pequeñas la retención de utilidades es casi nula. El marco teórico desarrollado en la sección 7 nos dará luces de las razones de este resultado.

\section{EL FUT EN LA PRÁCTICA}

Para clarificar las principales diferencias entre el régimen tributario antiguo (vigente antes del año 1984) y el régimen tributario que entró en vigencia con la Ley N. ${ }^{\circ} 18.293$, en esta sección presentamos un modelo simple que analiza cómo era el pago de impuestos de sociedades que operaban bajo diferentes esquemas tributarios. La razón de efectuar la comparación con el régimen tributario vigente hasta el 31 de diciembre de 1983 es que el régimen propuesto por la autoridad durante el primer semestre de 2014 contenía dentro de sus pilares más importantes (aunque más tarde fue parcialmente modificado) el establecimiento de la tributación en base a renta devengada, con la consiguiente supresión del FUT, lo que es sustancialmente similar al régimen previo a la Ley N. ${ }^{\circ} 18.293$.

Utilizando este marco de análisis, en la siguiente sección evaluaremos las políticas óptimas de retiro para sociedades que operan en el régimen previo a 1984 y post 1984. Dicho análisis nos permitirá evaluar cuál de los dos regímenes tributarios provee de mejores incentivos para la reinversión de utilidades.

Asumamos una economía pequeña y abierta que dura dos períodos (año 1 y año 2), en la cual los agentes prestan y se endeudan a una tasa de interés $r$, exógena al modelo. La tasa de inflación de la economía es cero $^{13}$. Cada agente de esta economía es dueño de una sociedad, la cual genera un flujo de utilidades igual a $Y 1$ en el año 1 y de $Y 2$ en el año 2.

${ }^{13}$ Este supuesto no afecta las conclusiones del análisis. 
A continuación mostramos el pago total de impuesto que se genera para distintos tipos de sociedades bajo el régimen tributario antiguo y el nuevo, en caso de retirar $R 1$ utilidades el primer período. Comenzaremos analizando cómo hubiese sido el pago de impuestos de las sociedades de personas y de las sociedades anónimas que operaban en el régimen tributario pre 1984. Luego veremos el caso de las mismas sociedades que se encuentran operando en el sistema tributario post 1984. En ambos casos, se ha asumido que los propietarios de estas sociedades son contribuyentes domiciliados o residentes en Chile, y, en consecuencia, afectos al impuesto global complementario.

\subsection{Tributación de sociedades anónimas bajo el régimen pre 1984}

La tabla 2 muestra cuál sería el pago de impuestos bajo el sistema tributario vigente hasta 1984 en sociedades anónimas que retiran un monto $R l$ de utilidades en el primer período. Bajo dicho esquema tributario, las utilidades generadas en el primer período tributan con el impuesto de primera categoría por un monto igual a $Y 1^{*} t p c$. Adicionalmente, dichas utilidades, una vez descontado el pago correspondiente al impuesto de primera categoría, están también sujetas a la tasa adicional, la cual conlleva un pago de impuestos de $Y 1 *(1-t p c) * t t a$. Después de pagar el impuesto de primera categoría y la tasa adicional, el dueño de esta sociedad tiene disponible para retirar hasta un monto máximo de $Y 1^{*}(1-t p c)^{*}(1-t t a)$, esto es, las utilidades que quedan después del pago de impuestos. Si la sociedad anónima distribuye a sus accionistas contribuyentes finales $R 1$ de las utilidades disponibles para ser distribuidas, los dueños de la sociedad anónima pagan un monto $R 1{ }^{*} \operatorname{tgc}(R 1)$ por concepto de global complementario, donde $\operatorname{tgc}(R 1)$ es la tasa promedio de global complementario que depende positivamente del monto de utilidades retiradas. El pago del global complementario considera un crédito derivado del pago de la tasa adicional y que es proporcional al monto de utilidades retiradas. Por ende, el monto del crédito equivale a $R 1 * t t a$. Si el crédito es mayor al pago de impuestos derivados del global complementario, el pago neto de este impuesto es simplemente cero.

En el segundo período, la sociedad anónima genera un flujo de $Y 2$. A este monto debemos sumarle los intereses generados por las utilidades que no fueron distribuidas durante el período 1 , esto es $(Y 1 *(1-$ $t p c) *(1-t t a)-R 1) * r$. Así, las utilidades totales generadas en el segundo 
período equivalen a $Y 2+(Y 1 *(1-t p c) *(1-t t a)-R 1) * r$. Esta es la base para el impuesto de primera categoría, cuyo pago involucra entonces recursos por un monto de $(Y 2+(Y 1 *(1-t p c) *(1-t t a)-R 1) * r) * t p c$. Al igual que en el primer período, sobre las utilidades que quedan después del pago del impuesto de primera categoría, la sociedad debe cancelar la tasa adicional por un monto igual a $(Y 2+(Y 1 *(1-t p c) *(1-t t a)-R 1) * r) *(1-$ $t p c)^{*} t t a$. Así, después del pago del impuesto de primera categoría y de la tasa adicional, tenemos que el monto máximo disponible para ser retirado es igual a $(Y 1 *(1-t p c) *(1-t t a)-R 1)+\left(Y 2+\left(Y 1^{*}(1-t p c) *(1-t t a)\right.\right.$ $R 1) * r) *(1-t p c) *(1-t t a)$, donde el primer término equivale a las utilidades que no fueron distribuidas en el primer período, mientras que el segundo término representa las utilidades después de impuestos generadas durante el segundo período.

Al distribuirse todas estas utilidades en el segundo período, la base para el global complementario de dicho período es igual a $(Y 1 *(1-$ $t p c) *(1-t t a)-R 1)+(Y 2+(Y 1 *(1-t p c) *(1-t t a)-R 1) * r) *(1-t p c) *(1-t t a)$. Al igual que antes, la tasa promedio del global complementario dependerá del monto distribuido $(\operatorname{tg} c(R 2))$. Respecto del crédito para el global complementario, éste se deriva del pago de la tasa adicional. La base de este crédito tiene dos componentes: primero, el crédito disponible no utilizado del primer período $(Y 1 *(1-t p c) *(1-t t a)-R 1)$; y segundo, las utilidades totales generadas en el periodo dos que serán distribuidas $(Y 2+(Y 1 *(1-t p c) *(1-t t a)-R 1) * r) *(1-t p c) *(1-t t a)$. Así, el crédito total disponible para ser utilizado contra el impuesto global complementario es igual a $[(Y 1 *(1-t p c) *(1-t t a)-R 1)+(Y 2+(Y 1 *(1-t p c) *(1-t t a)$ $R 1) * r) *(1-t p c) *(1-t t a)] * t t a$. Al igual que antes, si el crédito es mayor al pago de impuestos derivados del global complementario, la cancelación neta de este impuesto es simplemente cero.

\subsection{Tributación de sociedades de personas bajo el régimen pre $1984^{14}$}

A continuación, construiremos un ejemplo similar al anterior, esta vez para las sociedades de personas bajo el régimen vigente antes del

${ }^{14}$ Según el artículo $2^{\circ}$, n. ${ }^{\circ}$ 6, de la "Ley sobre impuesto a la renta", se consideran sociedades de personas "las sociedades de cualquier clase o denominación, excluyéndose únicamente a las anónimas". De acuerdo con la misma disposición, las sociedades por acciones ( $\mathrm{SpA}$ ) se consideran anónimas. 


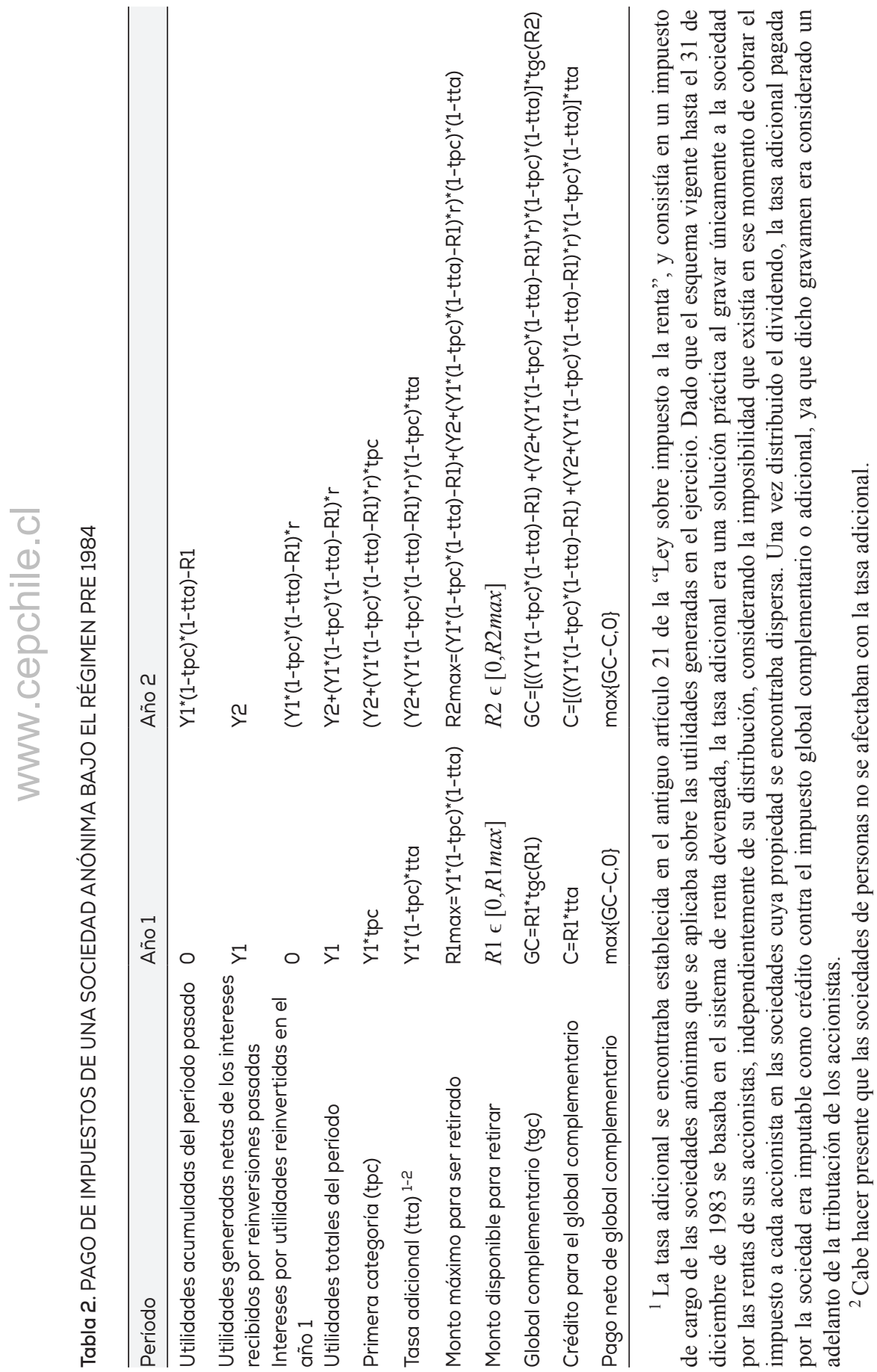


año 1984. La tabla 3 muestra el pago de impuestos de estas sociedades al retirar un monto $R 1$ de utilidades el primer período.

Las utilidades generadas en el primer período tributan, con el impuesto de primera categoría, un monto igual a $Y 1 * t p c$. Adicionalmente, independiente del monto retirado de utilidades, la base para el global complementario está dada por las utilidades generadas por la sociedad en el período. Esto porque el régimen antiguo consideraba una tributación en base devengada y no en base a retiros. Por ende, los socios personas naturales pagan un monto $Y 1 * \operatorname{tgc}(Y 1)$ de global complementario, independientemente del retiro o no de las utilidades del período ${ }^{15}$. La tasa promedio de este impuesto dependerá del tamaño de las utilidades generadas. Las utilidades del primer período que estarán disponibles para ser retiradas el segundo período son $Y 1 *(1-\operatorname{tpc}-\operatorname{tgc}(Y 1))-R 1$. Esto es, las utilidades generadas el primer período, menos el pago del impuesto de primera categoría $\left(Y 1^{*} t p c\right)$, menos el pago del global complementario $(Y 1 * \operatorname{tgc})$, menos las utilidades retiradas, $R 1$.

En el segundo período, la sociedad genera $Y 2$ de utilidades más los intereses producto de las utilidades no retiradas durante el primer período, $(Y 1 *(1-\operatorname{tpc}-\operatorname{tgc}(R 1))-R 1) * r$ (que, como se señaló, fueron afectadas con el impuesto global complementario). Las utilidades totales generadas en el segundo período (incluidos los intereses por el no retiro de las utilidades del primer período) constituyen la base para el impuesto de primera categoría y global complementario. Así, el pago por concepto de primera categoría es igual a $(Y 2+(Y 1 *(1-t p c-t g c(Y 1))-R 1) * r) * t p c$, mientras que los socios cancelan por concepto de global complementario $(Y 2+(Y 1 *(1-t p c)$ $R 1){ }^{*}$ ) ${ }^{*} \operatorname{tgc}(U T)$. En este caso, dado que la base del global complementario en el segundo período es el total de utilidades generadas (UT), éstas son las que determinan la tasa promedio de este impuesto.

\subsection{Tributación de sociedades bajo el régimen post 1984}

Finalmente, la tabla 4 muestra el pago de impuestos que se genera para los propietarios de las empresas al retirar o distribuir un monto $R 1$ de utilidades en el primer período, bajo el sistema tributario vigente

${ }^{15}$ Nótese que, por el hecho de que el régimen tributario vigente antes de 1984 no era un sistema tributario integrado, el pago del impuesto de primera categoría no era considerado un anticipo de los impuestos que debían pagar los socios como contribuyentes del global complementario y, por ende, existía una especie de doble tributación de las utilidades. 


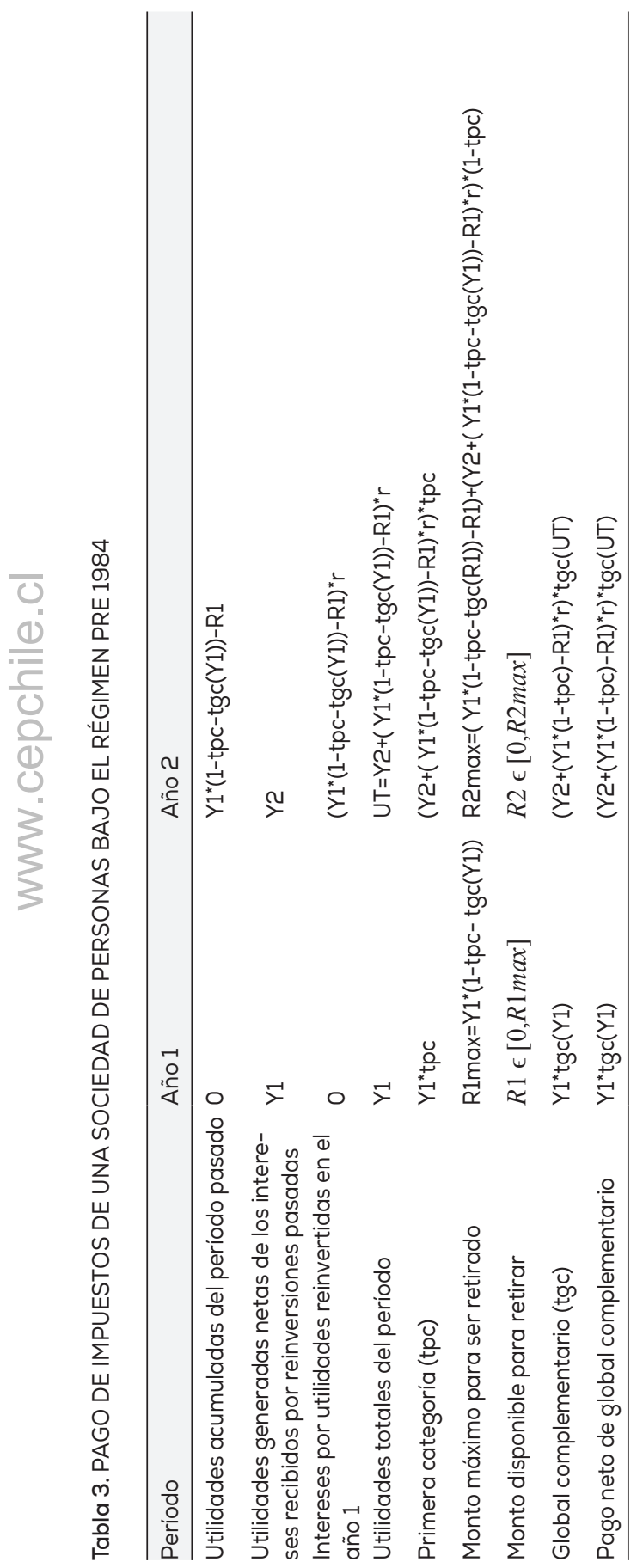




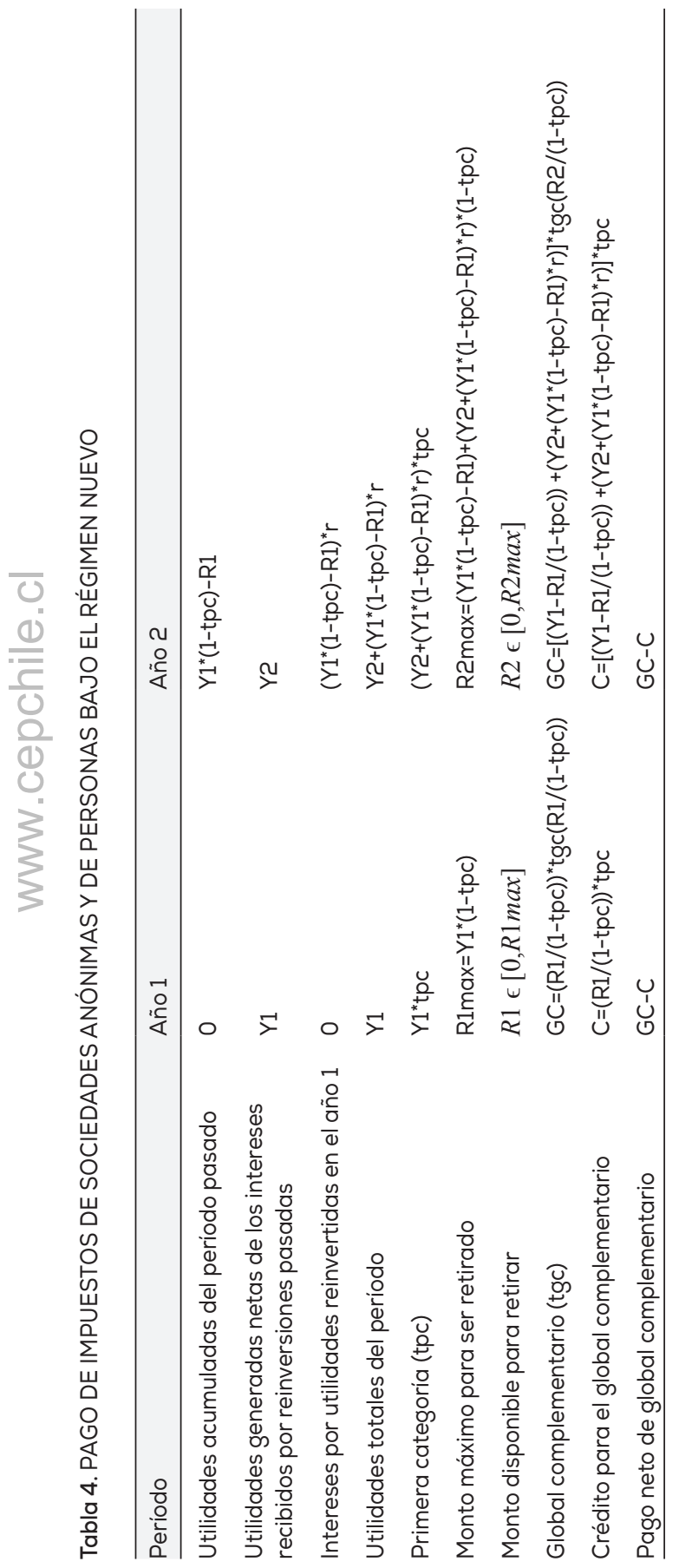


desde 1984. Tanto en las sociedades anónimas y de personas, las utilidades generadas en el primer período tributan con el impuesto de primera categoría un monto igual a $Y{ }^{*} t p c$, sin que se aplique el impuesto global complementario si las utilidades generadas por la empresa no son retiradas o distribuidas. Con esto, el monto máximo disponible para ser retirado en el primer período es de $Y 1^{*}(1-t p c)$.

Si los socios o accionistas retiran o se les distribuye un monto de utilidades de $R 1$, la base para la aplicación del impuesto global complementario considera dichas cantidades sin incluir el impuesto de primera categoría que se pagó por las utilidades retiradas o distribuidas ${ }^{16}$. Por ejemplo, si la totalidad de las utilidades fuera retirada o distribuida, el monto del retiro o dividendo sería igual a $R I=Y 1 *(1-t p c)$, y la base del impuesto global complementario sería de $R 1 /(1-t p c)=Y 1$. El monto total pagado por global complementario es de $R 1 /(1-t p c) * \operatorname{tg} c(R 1 /(1-t p c))$, donde vemos que la tasa promedio del impuesto depende del tamaño de la base impositiva. Cabe tener presente que el impuesto global complementario considera un crédito por el impuesto de primera categoría pagado, cuya base es la misma que la considerada para el global complementario. Esto último es consecuencia directa de un sistema tributario integrado. Así, el crédito tributario utilizado el primer período es de $R 1 /(1-t p c)^{*} t p c$.

En el segundo período, la sociedad del ejemplo genera utilidades equivalentes a $Y 2$. Adicionalmente, produce intereses por las utilidades no retiradas o distribuidas en el período anterior, $\left(Y 1^{*}(1-t p c)-R 1\right){ }^{*}$. Las utilidades totales generadas en el período constituyen la base para el impuesto de primera categoría. Así, el pago total de este impuesto es igual a $(Y 2+(Y 1 *(1-t p c)-R 1) * r) * t p c$. Adicionalmente, las utilidades totales generadas en el segundo período que quedan en la sociedad después del pago del impuesto de primera categoría, más aquellas no retiradas o distribuidas en el primer período, constituyen el monto máximo que puede ser retirado o distribuido en el segundo período. Dicho monto es igual a $(Y 1 *(1-t p c)-R 1)+(Y 2+(Y 1 *(1-t p c)-R 1) * r) *(1-t p c)$.

Si los socios retiran o la sociedad distribuye, en su caso, todos los recursos disponibles el segundo período, la base del global comple-

${ }^{16}$ Para simplificar los ejemplos de este trabajo, se ha omitido agregar a las cantidades retiradas o distribuidas de las empresas, afectas al impuesto global complementario, el monto equivalente al crédito correspondiente al impuesto de primera categoría que gravó tales cantidades, según lo establecido en el párrafo final, del numeral $1^{\circ}$, del artículo 54, de la "Ley sobre impuesto a la renta". 
mentario incluirá, primero, las utilidades acumuladas durante el primer período, sin considerar lo desembolsado por concepto del impuesto de primera categoría, esto es, $Y 1-R 1 /(1-t p c)$. A dicho monto, luego, se agrega la utilidad generada en el segundo período, también excluyendo el pago de primera categoría, $Y 2+(Y 1 *(1-t p c)-R 1) * r$. Con esto, el pago total del impuesto global complementario en el segundo período es igual a [Y1-R1/ $(1-t p c)+(Y 2+(Y 1 *(1-t p c)-R 1) * r)] * t g c(R 2 /(1-t p c))$. El crédito tributario imputable contra el impuesto global complementario se compone del crédito no utilizado en el primer período $(Y 1-R 1 /(1-t p c)) * t p c$ más lo tributado por primera categoría en el segundo período, $(Y 2+(Y 1 *(1-t p c)-R 1) * r) * t p c$.

\section{EL FUTY LOS INCENTIVOS A LA INVERSIÓN}

En esta sección estudiamos los incentivos a la reinversión que otorgaba el régimen tributario que comenzó a regir con la Ley N. ${ }^{\circ} 18.293$ respecto del sistema previo a éste. En particular, pondremos énfasis en el análisis de los incentivos a la reinversión que provee un sistema tributario en base a retiros en comparación con uno en base a utilidades devengadas. Esta diferencia en la base de la tributación de las rentas es uno de los principales elementos que distinguían entre ambos regímenes.

De la discusión en las secciones precedentes podemos ver que el cambio en la base de la tributación para el global complementario es particularmente relevante en el caso de las sociedades de personas. Por ende, en esta sección limitaremos el análisis a este tipo de sociedades.

Un primer elemento de incentivo a la inversión se origina en las restricciones de acceso al mercado de capitales que pudiesen enfrentar algunas empresas. El argumento es simple. Pensemos en una empresa que necesita financiar proyectos rentables de inversión, pero que no cuenta con fuentes externas de financiamiento. En este caso, su capacidad de llevar a cabo dichos proyectos de inversión dependerá exclusivamente de sus fuentes internas de financiamiento, es decir, de su flujo de utilidades que quedan después del pago de impuestos.

Un sistema tributario no integrado cuya tributación es en base a la renta devengada grava las utilidades generadas doblemente, con el impuesto de primera categoría y el global complementario. Ésta era precisamente la característica distintiva del régimen tributario que operó antes de 1984. Por el contrario, el sistema tributario que comenzó a regir con la publicación de la Ley N. ${ }^{0} 18.293$ instauró el principio de 
tributación de los propietarios de las empresas sobre la base de la renta percibida. Bajo este mecanismo, mientras las utilidades no fueran retiradas y se mantuvieran reinvertidas en la empresa, no se afectarían con los impuestos personales (global complementario o adicional, según el domicilio o residencia del contribuyente). Por ende, la tributación sobre la base de la renta percibida incrementa los fondos internos disponibles para la inversión en proyectos rentables y, con esto, las posibilidades de inversión. Esto es particularmente relevante para empresas que tienen acceso limitado al mercado de capitales.

En el caso en que un sistema tributario en base a renta devengada mantenga la integración de los impuestos como principio tributario, el incentivo a la inversión anteriormente descrito sólo sería relevante para empresas que generan flujos de utilidades altas. Esto porque, en dicho escenario, si la tasa efectiva del impuesto global complementario que pagan los propietarios de las empresas al momento de que se les distribuyan o retiren las utilidades es inferior o similar al impuesto de primera categoría pagado por la empresa, no existirá mucho incentivo en mantener las mismas utilidades invertidas en las empresas. De esta manera, el sistema en base a renta devengada realizaría, de manera automática, lo mismo que haría el contribuyente, es decir, distribuir o retirar las utilidades. Esto se explica en el hecho que si la tasa corporativa es superior a la tasa del impuesto global complementario, el contribuyente propietario de la empresa tendrá un incentivo evidente para que se le distribuyan o para retirar dichas utilidades, ya que de lo contrario el Fisco estaría reteniendo un impuesto (la diferencia entre el tributo corporativo y el tributo final) que al contribuyente final no le corresponde pagar. Lo anterior se traduce en que al momento de la distribución o retiro, el Fisco le devuelve al contribuyente la diferencia entre el impuesto de primera categoría retenido y el impuesto global complementario.

Un segundo elemento de incentivo a la inversión del FUT existe incluso en un mundo en que las empresas no tienen restricciones de acceso al mercado de capitales. Este elemento de incentivo a la inversión, tal como veremos, se origina al resolver un problema de "injusticia tributaria" o inequidad horizontal en el pago de impuestos que existe en un régimen que basa la tributación en la renta devengada y que, además, considera tasas marginales crecientes para los impuestos personales (global complementario), tal como sucedía en el sistema anterior a 1984. 
Considérense dos sociedades que generan el mismo flujo de ingresos en valor presente, pero en distintos momentos. Luego asumamos que estas sociedades operan en un mundo que dura sólo dos períodos. La sociedad $A$ genera una utilidad de $Y$ en ambos períodos. La sociedad $B$ genera un flujo de utilidades de $2 Y$ en el período 1, pero no genera utilidades en el período 2. Por simplicidad, asumamos que la tasa de interés es igual a cero. Nótese entonces que, en valor presente, ambas sociedades generan el mismo monto total de utilidades. Adicionalmente, asumiremos que al final del año 2, las personas deben consumir todo su ingreso (no hay herencias), por lo que retiran todos los recursos disponibles en la sociedad. Es decir, tal como ocurre en todo marco de análisis económico, al final de la vida, los agentes consumen todos sus recursos.

En la tabla 5, basados en el ejemplo de la tabla 3, tenemos que el pago total de impuestos de ambas sociedades bajo el régimen tributario pre 1984 es el siguiente:

Tabla 5. EJEMPLO PAGO DE IMPUESTOS SOCIEDADES A Y B BAJO EL RÉGIMEN PRE 1984

\begin{tabular}{llll}
\hline Periodo 1 & & Periodo 2 & \\
\hline Primera & Global & Primera & Global \\
categoría & complementario & categoria & complementario \\
\hline A $Y^{*} \operatorname{tpc}$ & $Y^{*} \operatorname{tgc}(Y)$ & $Y^{*} \operatorname{tpc}$ & $Y^{*} \operatorname{tgc}(Y)$ \\
$B \quad 2 Y^{*} \operatorname{tpc}$ & $2 Y^{*} \operatorname{tgc}(2 Y)$ & 0 & 0 \\
\hline
\end{tabular}

En la tabla anterior, podemos apreciar cómo si bien ambas sociedades generan, en valor presente de ingresos, el mismo monto de utilidades, terminan pagando un monto total distinto de impuestos. La razón detrás de esta "injusticia tributaria" es la progresividad del impuesto global complementario (es decir, el hecho de que $\operatorname{tgc}(2 Y)>\operatorname{tgc}(Y)$ ).

Veamos qué sucede en un sistema en que la tributación del global complementario es en base a la renta percibida y no a la devengada. La tabla 6 muestra el pago de impuestos de las sociedades $A$ y $B$ en el caso de que las sociedades retiren un monto $R l$ de utilidades en el período 1 . 
Tabla 6. EJEMPLO PAGO DE IMPUESTOS SOCIEDADES A Y B BAJO EL RÉGIMEN POST 1984

\begin{tabular}{|c|c|c|c|c|}
\hline \multicolumn{3}{|c|}{ Periodo 1} & \multicolumn{2}{|l|}{ Periodo 2} \\
\hline & $\begin{array}{l}\text { Primera } \\
\text { categoría }\end{array}$ & $\begin{array}{l}\text { Global } \\
\text { complementario }\end{array}$ & $\begin{array}{l}\text { Primera } \\
\text { categoria }\end{array}$ & $\begin{array}{l}\text { Global } \\
\text { complementario }\end{array}$ \\
\hline A & $Y^{*} \operatorname{tpc}$ & $(\mathrm{R} 1 /(1-\mathrm{tpc}))^{*}(\operatorname{tgc}(\mathrm{R} 1 /(1-\mathrm{tpc}))-\mathrm{tpc})$ & $Y^{*}$ tpc & $\begin{array}{l}(2 Y-R 1 /(1-\operatorname{tpc}))^{*}(\operatorname{tgc}(R 2 / \\
(1-\operatorname{tpc}))-\operatorname{tpc})\end{array}$ \\
\hline B & $2 Y^{*}$ tpc & $(R 1 /(1-t p c))^{*}(\operatorname{tgc}(R 1 /(1-t p c))-t p c)$ & 0 & $\begin{array}{l}(2 Y-R 1 /(1-\operatorname{tpc}))^{*}(\operatorname{tgc}(R 2 / \\
(1-\operatorname{tpc}))-\operatorname{tpc})\end{array}$ \\
\hline
\end{tabular}

El primer hecho interesante de notar es que si ambas sociedades deciden retirar el mismo monto de utilidades en el primer período, éstas pagan el mismo monto total de impuestos. Esta "justicia tributaria" o equidad tributaria horizontal es la consecuencia de un régimen en que la tributación es en base a renta percibida para los impuestos personales. La progresividad del impuesto global complementario actúa sobre el monto de las rentas efectivamente retiradas y no sobre aquellas generadas por la sociedad.

Segundo hecho interesante: asumamos que la función objetivo de los agentes es minimizar el pago total de impuestos. Para esto, los agentes eligen el monto óptimo de utilidades a retirar $R 1$ en el primer período. Así, el problema de optimización a resolver es el siguiente (1):

$\min _{R_{1}}\{T 1+T 2\}$

donde $T 1$ y $T 2$ corresponden al pago total de impuestos en el año 1 y el año 2 , respectivamente. La condición de primer orden para este problema de optimización es la siguiente (2):

$\left(\frac{\mathbf{1}}{1-t p c}\right) *\left(\operatorname{tgc}\left(\frac{\mathbf{R} 1}{\mathbf{1}-\mathbf{t p c}}\right)-\mathbf{t p c}\right)+\left(\frac{\mathbf{R} 1}{1-\mathbf{t p c}}\right) * \frac{\partial t g c}{\partial R}-\left(\frac{\mathbf{1}}{\mathbf{1}-t p c}\right) *\left(\operatorname{tgc}\left(\frac{\mathbf{R} 2}{\mathbf{1}-\mathbf{t p c}}\right)-\mathbf{t p c}\right)-\left(\frac{\mathbf{R} 1}{1-\mathbf{t p c}}\right) * \frac{\partial t g c}{\partial R}=\mathbf{0}$

La condición de primer orden nos muestra los costos (mayor pago total de impuestos) y beneficios (menor pago total de impuestos) de retirar pesos adicionales en el primer período. Al realizar este retiro, se incrementa la base y tasa promedio del impuesto global complementario del primer período (primer y segundo término de la ecuación (2)). Por su parte, la menor retención de utilidades reduce la base y tasa promedio de dicho impuesto en el segundo período (tercer y cuarto término de 
la ecuación (2)). Nótese que la condición de primer orden descrita por la ecuación (2) se satisface para un nivel de retiros de utilidades igual a $R 1=Y^{*}(1-t p c)$, es decir, el máximo nivel de utilidades posibles para ser retiradas en una sociedad que genera utilidades igual a $Y$ en dicho período. Dado ese retiro de utilidades en el primer período, la sociedad B termina pagando el mismo total de impuestos que la sociedad A.

La intuición de por qué una política de retiros estables en el tiempo es la que minimiza el pago de impuestos es la siguiente. Asumamos que existen sólo dos tramos para el impuesto global complementario. Hasta un retiro de $X 1$, los socios pagan un impuesto global complementario de $a \%$. Sobre esos $X 1$ pesos retirados, la tasa del global complementario sube a $b \%>a \%$. Entonces, en una sociedad que se generan utilidades por un monto mayor a $X 1$ en un primer período, pero que no genera utilidades en el segundo período, por cada peso de utilidades que retiene por sobre los $X 1$ pesos, se reduce la tasa de global complementario desde $b \%$ a $a \%$. Esto explica por qué para la sociedad $B$, de nuestro ejemplo, una política de retención parcial de utilidades minimiza su pago total de impuestos.

Por ende, podemos concluir que el sistema tributario en vigencia desde 1984 hasta la reforma de $2014^{17}$ genera incentivos tributarios a la reinversión de utilidades que son particularmente relevantes para sociedades con flujos de utilidades que son inestables en el tiempo (específicamente, decrecientes). Esto, porque al retener utilidades, sociedades que generan flujos inestables de utilidades suavizan el pago del global complementario en el tiempo, lo cual minimiza el pago de impuesto dada la progresividad marginal de este gravamen. Este efecto es independiente del grado de integración de los impuestos en el sistema tributario y sólo se origina por el hecho de poder diferir en el tiempo el pago del global complementario. Además, este sistema genera una "justicia tributaria" o equidad tributaria horizontal, en el sentido de que permite que sociedades (socios) que generan el mismo monto de utilidades, pero en distintos momentos, paguen el mismo monto total de impuestos.

Finalmente, nótese que, de no existir la progresividad del global complementario $\left(\frac{\partial \operatorname{tgc}}{\partial \mathrm{R}}=0 \mathrm{y} \operatorname{tgc}\left(\frac{\mathrm{R} 1}{1-\mathrm{tp}_{\mathrm{c}}}\right)=\operatorname{tgc}\right)$, la solución al proble-

${ }^{17}$ Aún en discusión en el Congreso al cierre de este número de Estudios Públicos (N. del E.) 
ma de minimización descrito por la ecuación (1) está indeterminada. Es decir, la sociedad estaría indiferente entre retirar distintos montos de utilidades en el primer período. Esto, porque un menor pago de impuesto global complementario en el primer período se compensa con un mayor pago en el segundo período a la misma tasa promedio de dicho impuesto.

\section{EL DEBATE SOBRE EL TRATAMIENTO DEL IMPUESTO A LA RENTA}

De las secciones precedentes podemos concluir que si la finalidad del FUT continúa siendo aquélla para lo cual fue creado —el incentivo al ahorro e inversión-, la eliminación del FUT y el movimiento hacia un régimen tributario en base devengada no es recomendable. Esta conclusión está en línea con la de algunos trabajos existentes en la literatura, tales como el de Arellano y Corbo (2013). Dichos autores concluyen que el régimen de tributación en base a retiros ha sido un estímulo al ahorro en las empresas o sociedades y una fuente de financiamiento para la inversión vía reinversión de utilidades, contribuyendo así a que en las últimas décadas el ahorro de empresas represente una fracción significativa del ahorro nacional.

Sin embargo, a pesar de los incentivos al ahorro e inversión que ha otorgado el régimen en base a retiros, éste no ha estado exento de debate. Por el contrario, el tratamiento del ingreso a la renta ha sido un foco permanente en el debate público, existiendo diversas posturas al respecto. Mientras algunos estudios apoyan la idea de que un régimen tributario en base a retiros incentivaría el ahorro y la inversión, tal como lo hace el estudio de Arellano y Corbo (2013) y el nuestro, otros sostienen que se ha convertido en una fuente importante de elusión y evasión de impuestos y que afectaría la equidad horizontal de nuestro sistema tributario. A continuación, revisaremos brevemente el debate que se ha desarrollado en torno a este tema. Luego, discutiremos algunas de las propuestas de modificación al sistema tributario que han emergido en la literatura.

\subsection{El debate en la literatura}

Un primer punto de discusión en el debate dice relación con el efecto de los impuestos sobre la inversión. Tal como hemos concluido en este trabajo, el esquema de tributación en base a rentas percibidas 
estimula la reinversión de las utilidades en la medida en que los retiros son castigados con una alta tasa impositiva. Para entender cuán importante es este efecto, debemos primero tener alguna noción de los efectos empíricos de la demanda por capital frente a cambios impositivos. Esto, porque si se pasara desde un régimen en base a retiros hacia uno en base devengada, las utilidades tributarían no sólo por la tasa de impuesto corporativa, sino que también por los impuestos terminales - global complementario o adicional, según el domicilio o residencia del beneficiario-, lo que en definitiva incrementaría la tasa de impuesto efectiva en algunas empresas, incluso manteniendo intacta la integración de tributos entre empresas y personas ${ }^{18}$. A nivel empírico, la literatura entrega resultados variados. Estudios como el de Engel et al. (1998) y el de Bustos et al. (2004) concluyen que la demanda agregada de capital no es sensible a la tasa del impuesto a las utilidades retenidas. Por su parte, Cerda y Larraín (2005), Cerda y Saravia (2009), Hsieh y Parker (2007), Medina y Valdés (1998) y Vergara (2010) sugieren que los impuestos a las utilidades afectan negativamente las decisiones de inversión en algunos tipos de empresas. Por ende, la literatura aún no nos entrega una respuesta concluyente respecto de este primer punto.

Un segundo elemento central del debate dice relación con los efectos que generaba el sistema vigente antes de la reforma tributaria del año 2014 sobre la equidad horizontal del sistema impositivo. El FUT sólo podía ser llevado por empresas que son contribuyentes del impuesto de primera categoría con contabilidad completa ${ }^{19}$, mientras que los contribuyentes del impuesto de segunda categoría no contaban con esta opción. Por ende, una misma actividad podía tener distintos tratamientos tributarios, al permitirse en un caso la tributación en base a retiros, frente a la renta devengada en el otro. Esto rompía el principio de equidad tributaria horizontal, ya que algunas actividades que por su naturaleza debiesen tributar con impuesto global comple-

18 Por ejemplo, Jorratt (2009) muestra que en el año 2006 las rentas empresariales pagaron un impuesto promedio de 15,2 por ciento, en tanto que de haber tributado sobre base devengada habrían soportado una carga de 26,5 por ciento.

${ }^{19}$ El inciso final del artículo 68 de la "Ley sobre impuesto a la renta" establece el deber de llevar contabilidad completa como la regla general para todos los contribuyentes de dicha ley. 
mentario (pues se trata de actividades mencionadas en el artículo 42, n. 2 , de la "Ley sobre impuesto a la renta") se tratan como rentas del capital para efectos de llevar el FUT, sin atender necesariamente al hecho de si, para la generación de estos ingresos, predomina o no el uso del capital por sobre el trabajo personal, lo cual es el elemento primordial para la aplicación del impuesto de primera categoría. Cabe mencionar, sin embargo, que en ambos casos se permitía deducir los gastos producidos en la generación de rentas, y en el caso de los profesionales independientes, éstos podían optar entre una presunción de gastos equivalente al 30 por ciento de sus ingresos brutos, con un tope anual de 15 UTA, o deducir sus gastos efectivos aplicando las mismas reglas que las empresas.

Lo descrito anteriormente puede graficarse en el siguiente ejemplo: por los servicios personales que presta un profesional independiente, recibe una remuneración u honorario, por la cual deberá pagar el impuesto global complementario respecto de los pagos que se le realicen, sobre renta percibida, emitiendo la correspondiente boleta de honorarios. Al aplicarse el impuesto sobre base percibida, el profesional no puede influir sustancialmente en el monto de su impuesto anual a pagar (como sí podría hacerlo si llevara un FUT, según fuera explicado anteriormente). Pero si el mismo profesional constituye una sociedad, por ejemplo, de asesorías y servicios profesionales, y presta a través de ella idénticos servicios (nótese que en ambos casos se trata de su trabajo personal), la remuneración que obtenga la sociedad se afectará con el impuesto de primera categoría e ingresará a su FUT, gravándose con impuesto global complementario cuando sea retirada por el socio. La inequidad en este caso surge porque el profesional que, por falta de acceso a la información o de recursos, no está en condiciones de constituir una sociedad y de cumplir las obligaciones anexas que establece la legislación tributaria, como llevar contabilidad, efectuar pagos provisionales mensuales, etcétera, no puede tributar en base a retiros, como sí puede hacerlo el contribuyente que realiza su actividad profesional a través de una sociedad. Adicionalmente, hoy el contribuyente que lleva contabilidad completa y FUT puede optar a regímenes especiales de tributación a los que tampoco tiene acceso el profesional liberal, como por ejem- 
plo el de los artículos 14 bis $^{20}$ y 14 quáter ${ }^{21}$ de la "Ley sobre impuesto a la renta".

Por su parte, los contribuyentes del impuesto único de segunda categoría (trabajadores dependientes) tampoco pueden utilizar el FUT como moderador de su base imponible e igualmente tributan sobre base percibida. No obstante, estos trabajadores no tienen la posibilidad de deducir gastos efectivos en la generación de sus ingresos, como sí pueden hacerlo los profesionales independientes y los demás contribuyentes del artículo 42, n. ${ }^{\circ} 2$, de la "Ley sobre impuesto a la renta", que ejerzan su profesión u ocupación en forma individual.

En aras de la equidad, la legislación en discusión podría considerar un sistema en base a retiros para los contribuyentes del impuesto global complementario, o incluso para los del impuesto único de segunda

${ }^{20}$ El régimen de tributación simplificada que contempla el artículo 14 bis de la "Ley sobre impuesto a la renta", cuya derogación fue propuesta por el proyecto de ley de reforma tributaria que a la fecha de edición de este trabajo se discutía en el Congreso, consiste en un beneficio tributario que pueden utilizar los contribuyentes obligados a declarar renta efectiva según contabilidad completa, por las rentas del artículo 20 de la "Ley sobre impuesto a la renta", siempre y cuando cumplan con los requisitos que señala dicho artículo. Este régimen especial de tributación da la opción de pagar los impuestos anuales de primera categoría y global complementario o adicional, sobre todos los retiros en dinero o en especies que efectúen los propietarios, socios o comuneros, y todas las cantidades que distribuyan a cualquier título las sociedades anónimas o en comandita por acciones, sin distinguir o considerar su origen o fuente, o si se trata o no de sumas no gravadas o exentas. Por lo tanto, permite postergar el pago del impuesto de primera categoría mientras no se retiren los recursos. Los contribuyentes que se acogían al 14 bis se beneficiaban adicionalmente eximiéndose de otras obligaciones tributarias, tales como llevar el detalle de las utilidades tributarias y otros ingresos que se contabilizaban en el Registro de la Renta Líquida Imponible de Primera Categoría y Utilidades Acumuladas; practicar inventarios; confeccionar el balance general anual, etcétera. Al no existir FUT, la empresa no tributa con el impuesto de primera categoría sobre sus rentas devengadas, sino que la totalidad del impuesto a la renta es pagado por el propietario o contribuyente final cuando las utilidades son retiradas o distribuidas desde la sociedad

${ }^{21}$ El artículo 14 quáter de la "Ley sobre impuesto a la renta" establece un régimen optativo que permite a los contribuyentes que cumplen con las condiciones y requisitos que se exigen quedar exentos del Impuesto de Primera Categoría. El beneficio al que se puede acceder consiste en que se considerará como renta exenta del impuesto de primera categoría el monto de 1.440 unidades tributarias mensuales (UTM), equivalentes a unos \$ 54 millones. Adicionalmente, reduce el porcentaje de Pagos Provisionales Mensuales (PPM) a 0,25\%. 
categoría $^{22}$. De esta forma, el sistema tributario alcanzaría la equidad tributaria horizontal ("entre iguales los impuestos deben ser iguales") por dos canales. Primero, al hacer que sociedades que generan el mismo flujo de utilidades en valor presente pero en distintos momentos paguen los mismos impuestos, lo cual ya se lograba con el sistema vigente desde 1984. Segundo, al hacer que agentes que desempeñan las mismas actividades paguen los mismos impuestos, independientemente de si producen o no sus servicios bajo el amparo de una sociedad. Es por lo tanto un FUT “ampliado" lo que verdaderamente lograría la equidad horizontal en el pago de impuestos. Quiroz y Schmidt-Hebbel (2013) elaboran una propuesta en esa línea, tal como veremos en la sección 8.2 de este trabajo.

Como fue sugerido, un tercer elemento en el debate tributario sobre el tratamiento del impuesto a la renta se relaciona con los espacios que dejaría un sistema impositivo en base a renta percibida para la evasión y elusión de impuestos. Por ejemplo, un problema surge cuando, a modo de evitar el pago del impuesto global complementario, los agentes declaran su consumo privado como gastos propios de la sociedad ${ }^{23}$. Diversos estudios discuten éste y otros espacios de evasión y elusión de impuestos que generaría un sistema en base a retiros.

Jorratt (2009) ha argumentado que la brecha entre la tasa del impuesto de primera categoría y la tasa máxima del impuesto global complementario, más la tributación de las utilidades sobre base retirada, genera incentivos a la elusión que debiesen ser frenados a través

${ }^{22}$ Es necesario hacer presente que, con el actual sistema de Ahorro Previsional Voluntario (APV), los cotizantes pueden lograr un efecto similar al comentado, en el sentido de suavizar sus tasas de impuesto global complementario y único de segunda categoría, evitando que la carga tributaria se eleve cuando obtienen rentas altas, asignando retiros previsionales cuando se encuentran en tramos inferiores de impuesto. No obstante, en el caso de los trabajadores independientes, este escenario supone una cotización provisional, la que será obligatoria recién a contar del año 2015, y en el caso de trabajadores dependientes e independientes, se asume que pueden destinarse sumas a hacer APV, lo que implica la existencia de un excedente de recursos para ser invertidos en una AFP.

${ }^{23}$ En todo caso, cabe tener presente que, especialmente luego de la Ley N. ${ }^{\circ} 19.738$, de 2001, muchas de estas situaciones quedaron superadas al establecerse mecanismos para evitar que sucedan. En consecuencia, se puede sostener que, aunque aún existen situaciones que pueden corregirse, la realización de gastos personales de los socios a través de sus sociedades, eludiendo la tributación con impuestos finales, se encuentra controlada desde el punto de vista normativo. 
de normas, tales como la presunción de retiros o la tributación especial sobre gastos rechazados. Además, ha señalado que la tributación de las utilidades sobre base retirada deriva también en la necesidad de utilizar el FUT. El autor ha afirmado que este registro es único en el mundo y que constituía uno de los aspectos más engorrosos del sistema impositivo en Chile. Por ende, el tratamiento preferencial a las rentas empresariales aumenta la complejidad del impuesto a la renta, lo que implica mayores costos de cumplimiento y de administración del sistema. En la misma línea, Contreras y Repetto (2013) han señalado que si bien la tributación en base a utilidades distribuidas posee fuertes incentivos al ahorro e inversión, el principal problema del sistema radica en que en los segmentos altos este mecanismo se utiliza para la evasión y elusión de impuestos. La razón, según los autores, radica en lo engorroso que resultaba para el SII la fiscalización del FUT y la incapacidad de este servicio para monitorear un sistema que resultaba ser complejo.

Adicionalmente, Zee (1998) señala que este esquema podría haber sido fuente de importantes costos en términos de recaudación, eficiencia y equidad, los cuales deben ser cuidadosamente ponderados frente a los eventuales beneficios que se le atribuyen. A su juicio, los principales costos han sido: la excesiva creación de empresas por razones exclusivamente tributarias; la excesiva retención de utilidades en las empresas, lo cual distorsiona el mercado de capitales; y la inequidad que produce en el impuesto progresivo a las personas, cuya carga cae pesadamente sobre los ingresos del trabajo.

En línea con los estudios anteriores, Arellano y Corbo (2013) señalan que un esquema de tributación en base a retiros genera un incentivo a formar sociedades con el único propósito de beneficiarse de este mecanismo de tributación al momento del retiro. Adicionalmente, los autores afirman que este sistema es más fácil de eludir, ya que las utilidades podrían tributar muchos años después de haber sido generadas. Por su parte, en un sistema en que se gravan las utilidades devengadas, las tasas de impuesto a las personas pueden ser más bajas, reduciendo las diferencias entre el tratamiento a los ingresos del trabajo y del capital, y disminuyendo los incentivos a la formación de sociedades y evasión o elusión tributaria.

Un último punto importante de debate en la literatura es el levantado por Contreras y Repetto (2013). Estos autores han afirmado 
que el tratamiento tributario de las utilidades en Chile representa una excepción a nivel internacional. Sin embargo, Bravo et al. (2014) argumentan lo contrario, ya que sostienen que en muchas partes del mundo se realiza la tributación en base a retiros por medio de lo que se conoce como impuesto a los dividendos (dividend tax). En este tipo de tributos las empresas pagan cuando se devenga pero los socios sólo cuando retiran, similar a lo que ocurría en Chile previamente a la reforma actual en curso. Respecto de la integración de los impuestos, la aseveración de Contreras y Repetto (2013) contrasta con la evidencia que muestran estudios sobre sistemas tributarios comparados, en que se observa que varias economías tienen sistemas tributarios integrados muy similares al chileno ${ }^{24}$. Por su parte, una de las conclusiones del reporte Mirrlees (2011) es que sistemas tributarios no integrados producen elementos de complejidad e introducen oportunidades de elusión.

\subsection{Propuestas en la literatura}

Basados en los argumentos resumidos anteriormente, han emergido en la literatura estudios que han propuesto algunas modificaciones al sistema tributario chileno, específicamente al tratamiento del impuesto a la renta. Podemos distinguir tres grupos de propuestas. Primero, aquellas que han planteado cambiar la base de la tributación (desde una en base a retiros hacia una en base devengada), con la consecuente eliminación del FUT. Este tipo de iniciativas han sido acompañadas, en algunas ocasiones, con medidas de incentivos alternativos al ahorro e inversión. En segundo lugar, encontramos planteamientos que presentan cambios alternativos al sistema tributario, que buscan recaudar los recursos necesarios para financiar la reforma educacional del actual Gobierno, pero utilizando esquemas impositivos más eficientes. En tercer

${ }^{24} \mathrm{La}$ base de datos tributarios de la Organización para la Cooperación y el Desarrollo Económicos (OCDE 2014) muestra que al año 2013, considerando sólo sus países miembros, Australia, Canadá, Chile, México y Nueva Zelandia tienen sistemas tributarios completamente integrados, mientras que Corea del Sur y el Reino Unido presentan sistemas tributarios parcialmente integrados. De aprobarse el proyecto de ley de reforma tributaria (Boletín número 9.290-05), en tramitación a la fecha de publicación de este artículo, en los términos del protocolo de acuerdo logrado en el Senado durante la primera mitad de julio de 2014, Chile pasaría a estar en el grupo de economías que presentan un sistema tributario parcialmente integrado. 
lugar, encontramos propuestas que abogan por mantener el FUT, pero corrigiendo aquellos aspectos que la literatura ha identificado como sus principales falencias.

Entre el primer grupo de propuestas encontramos las de Agostini (2011) y Contreras y Repetto (2013), que han planteado la modificación del esquema de tributación de las utilidades desde base distribuida a base devengada, manteniendo la integración de los impuestos de personas y empresas. Dichos trabajos sugieren complementar el cambio en la base de tributación con la deducción (o depreciación) inmediata de los gastos en inversión en activos físicos al interior de la empresa, a modo de aliviar la situación financiera de empresas que pudiesen enfrentar problemas de liquidez. Similarmente, Jorratt (2009) ha señalado que sería posible suprimir el registro FUT, terminar con las presunciones de rentas personales por el uso de los activos de la empresa y simplificar la tributación especial sobre gastos rechazados. El estudio concluye que estos cambios al sistema tributario desincentivarían gran parte de las figuras de elusión y evasión observadas en el sistema, en particular la creación de sociedades de inversión con fines exclusivamente tributarios, tal vez la principal forma de elusión de los impuestos personales.

Sin embargo, Valdés (2014) ha argumentado que un sistema impositivo en base devengada presenta problemas prácticos para su implementación. El paso de un régimen de tributación desde base de retiros a base devengada contiene implícitamente la llamada utilidad "atribuida", lo cual vuelve el sistema de recaudación de los impuestos difícil de operar. El argumento de Valdés (2014) ha sido el siguiente:

Un sistema impositivo en base devengada genera la necesidad de que las empresas atribuyan utilidades a las personas naturales a modo de calcular el pago de impuestos del contribuyente. Cada persona natural contaría con sólo algunos días para averiguar cuánta es la utilidad que le atribuyeron todas las empresas chilenas donde posee derechos, a modo de cumplir con sus obligaciones tributarias. Además, cada empresa debe determinar la utilidad que se atribuye a sí misma, lo cual requiere que la empresa solicite a otras sociedades donde tiene participación que le atribuyan utilidades. Este proceso requiere muchas iteraciones antes de poder determinar el pago final de impuestos que debe realizar cada contribuyente. Además, si un eslabón de la cadena incumple o se atrasa, todas las empresas que siguen en la cadena que- 
dan impedidas de determinar su utilidad. Por el contrario, bajo el régimen vigente, cada contribuyente cuenta con la información necesaria para determinarla. Este requerimiento modesto de información, según el autor, es lo que vuelve practicable el sistema actual (tributación en base percibida). Para más detalle, véase Valdés (2014).

Este obstáculo operacional del sistema de renta atribuida también ha sido detectado por otros autores. Por ejemplo, Agostini señala: "Una de las mayores dificultades en el proceso de asignar utilidades de empresas a socios es que hay muchas sociedades que tienen como socios a otras sociedades, lo cual requiere múltiples iteraciones hasta poder identificar al socio que es persona natural" $(2013,8)$. En la misma línea que Agostini (2013) y Valdés (2014), la OCDE documenta que, según las legislaciones de todos sus países miembros, las utilidades de las sociedades no pueden ser atribuidas a sus accionistas, salvo ciertas situaciones excepcionales (OCDE 2010, 193).

Nótese que la dificultad para operar un sistema que requiere la atribución de utilidades constituye un problema adicional a los menores incentivos a la inversión que provee un régimen de tributación en base devengada.

En el segundo grupo de propuestas, tenemos aquellas que han planteado alternativas para la eliminación del FUT, como, por ejemplo, el cobro a los socios de un "interés" por mantener invertidas las utilidades en las empresas, derivado del beneficio de postergar la tributación con impuestos finales, cuestión que fue planteada por Andrés Velasco en su campaña por la primaria presidencial del año $2013^{25}$. También se ha planteado la idea de que el beneficio para los dueños de las empresas de postergar el pago de impuestos al reinvertir las utilidades se limite a diez años como máximo, y no hasta que se hagan los retiros de esas utilidades. De esta forma se conseguiría mantener el incentivo al ahorro corporativo acotado en el tiempo, con el fin de evitar su distorsión

${ }^{25}$ En todo caso, la mantención de las utilidades dentro del FUT de las empresas, sin que éstas sean retiradas, implica también un costo financiero para los propietarios de las mismas empresas, el que podría asimilarse conceptualmente a un interés. De hecho, en el caso de contribuyentes que se encuentran en un tramo promedio de impuesto global complementario inferior a la tasa de impuesto de primera categoría, el no retiro de las utilidades implica dejar de invertir un monto equivalente a la diferencia entre el impuesto de primera categoría y el impuesto global complementario que afectaría dicho retiro. 
como instrumento de elusión tributaria. Aunque en el papel esta propuesta recaudaría menos que una propuesta de eliminar derechamente el FUT, podría ser equivalente en la práctica, si consigue no afectar significativamente el incentivo a la reinversión de utilidades, la inversión y, finalmente, el crecimiento económico, pilar esencial de la recaudación de impuestos (Morandé 2014).

En este grupo de propuestas también encontramos la de Quiroz y Schmidt-Hebbel (2013). Dicho estudio discute dos alternativas a modo de lograr una mayor equidad horizontal del sistema tributario. Primero, proponen sustituir la base tributaria de ingreso por una base consumo para las personas. Así, bajo esta alternativa, la base tributaria estaría dada por el gasto o consumo de las personas, definido como los ingresos menos los flujos de ahorros (incluyendo préstamos) y más los flujos de "desahorros" (incluyendo endeudamientos). Como el impuesto al consumo no considera el ahorro en su base imponible, no genera esta inequidad horizontal, porque cualquier instrumento de ahorro y mecanismo de ahorro (como persona natural o a través de una sociedad de inversión) se trata en forma equivalente ${ }^{26}$. Alternativamente, proponen mantener la base ingreso para la tributación, pero permitir a los trabajadores dependientes formar una sociedad personal para recibir sus sueldos y salarios sujetos a un tope como porcentaje de la renta total. Esta alternativa permite alcanzar la equidad horizontal entre trabajadores dependientes (que hoy no pueden recibir sus ingresos a través de una sociedad) y trabajadores independientes (que muchas veces pueden recibir sus honorarios a través de una sociedad), sin necesidad de sustituir la actual base ingreso del impuesto a la renta.

En el tercer grupo se encuentran planteamientos como el de Arellano y Corbo (2013), una propuesta que, manteniendo el sistema actual en que se paga sobre la base de retiros de utilidades, lograría el objetivo

${ }^{26}$ Esta afirmación no es aplicable en el caso del tributo municipal denominado comúnmente patente comercial o municipal, ya que, a nuestro juicio, por una interpretación errónea que han efectuado las municipalidades y, en el último tiempo, los tribunales superiores de justicia, incluso contra la jurisprudencia reiterada de la Contraloría General de la República, las inversiones "pasivas" realizadas por una persona jurídica se afectan con este tributo, mientras que una inversión de idéntica naturaleza, realizada por una persona natural, no cae dentro del hecho gravado con patente municipal. En todo caso, vale mencionar que la patente municipal es un tributo que se aplica sobre el patrimonio, y no sobre la renta. 
de mayor equidad horizontal y eficiencia. El estudio señala que para esto se requiere avanzar en reducir exenciones y regímenes especiales por sus efectos en la equidad y la progresividad. Por ende, el reemplazo de los regímenes especiales de renta presunta, del 14 bis y del 14 quáter por el 14 ter sería una medida recomendable. También proponen generalizar el sistema que grava a las empresas, asimilando todos los casos al régimen tributario que se aplica a las sociedades anónimas, incluyendo los Fondos de Inversión Privados (FIP). Al respecto, los autores señalan que no es conveniente que el régimen tributario de la renta a las empresas difiera dependiendo de si se trata de una sociedad anónima o no, con la única excepción de quienes se acogen al 14 ter. Para asimilar el trato de sociedades de personas al de las sociedades anónimas, los autores proponen revisar el tratamiento de los retiros de utilidades financieras que superan las utilidades tributarias en las sociedades de personas, así como el tratamiento de los gastos rechazados. También recomiendan revisar el tratamiento de las pérdidas tributarias y el plazo y situaciones en que se pueden acreditar contra otros impuestos.

Bravo et al. (2014), por último, proponen una reforma alternativa que recaudaría cerca de 8.200 millones de dólares por año al 2018, cifra equivalente a la que busca recaudar el Gobierno para financiar la reforma educacional. La propuesta no elimina el incentivo al ahorro del FUT ni deroga regímenes tributarios que favorecen a las micro, pequeñas y medianas empresas. Específicamente, los autores proponen: 1) un aumento de la Tasa de Impuesto de Primera Categoría de 20 a 25 por ciento al año calendario 2017 ; 2) homologar el requisito de distribución mínima de utilidades de las sociedades anónimas abiertas a todas las empresas y aumentarlo desde el actual 30 por ciento a un 40;3) regular la tributación de los retiros en exceso; 4) eliminar exención de IVA a juegos de azar y espectáculos; 5) aumentar el impuesto adicional a las bebidas de mayor graduación alcohólica; 6) mantener las medidas para disminuir la evasión y elusión tributaria del proyecto del Gobierno; 7) establecer un impuesto a la primera venta de productos cuyos residuos son contaminantes, lo que incluye neumáticos, aceites, lubricantes, pilas, baterías, ampolletas, envases y embalajes, mediante una tasa de impuesto en UTM que se pagaría mensualmente, y contemplar una devolución de impuestos a quienes puedan acreditar que reutilizan el material de sus envases; y 8) rebaja de la tasa marginal máxima del impuesto a la renta personal de 40 a 35 por ciento. 


\subsection{Las reformas tributarias del periodo 2010-2014}

Es necesario recordar que, a comienzos del año 2010, la tasa del impuesto de primera categoría era de 17 por ciento. En las postrimerías del primer Gobierno de Michelle Bachelet, el 27 de febrero de 2010, el país fue víctima de una de las mayores catástrofes naturales de su historia, cuando un terremoto y posteriormente un maremoto arrasaron con vastas áreas costeras, llevándose numerosas vidas y derrumbando infraestructura, dejando cuantiosos daños.

En atención a esta tragedia, el Gobierno del recién asumido Presidente Piñera comienza la difícil tarea de obtener recursos para la reconstrucción de las zonas destruidas por el terremoto y maremoto. Con ese fin, se aprueba la Ley N. ${ }^{\circ} 20.455$, la que, entre otras materias, aumentó transitoriamente la tasa del impuesto de primera categoría a 20 por ciento para el año 2011 y a 18,5 por ciento el año 2012, debiendo retornar a la tasa normal de 17 por ciento a contar del año calendario 2013. No obstante, y como suele ocurrir con los incrementos transitorios de impuestos, la segunda ley de reforma tributaria importante aprobada durante el Gobierno de Piñera (N. ${ }^{\circ}$ 20.630) elevó de manera permanente la tasa del impuesto de primera categoría a 20 por ciento. Adicionalmente a este cambio, el proyecto de ley incorporaba, al menos en su primera versión, importantes modificaciones y perfeccionamientos al FUT, los que posteriormente, en la indicación sustitutiva enviada por el Ejecutivo, fueron moderados. Lo que quedaba claro es que la discusión tributaria comenzaba a instalarse en el ambiente político, tanto así que, durante la campaña electoral presidencial del año 2013, prácticamente todos los candidatos a la presidencia prometían programas de gobierno con propuestas tributarias de bastante profundidad.

El programa de gobierno de la, en ese entonces, candidata Michelle Bachelet no se restó a esta tendencia, y estableció los principios de una reforma tributaria cuya principal consigna era acabar con el FUT, al que se sindicaba como una de las principales causas de la desigualdad en Chile. Como complemento a esta medida, y con miras a la recaudación, el programa proponía además reducir la evasión y la elusión y el término de ciertas franquicias. Una vez electa por un segundo período, y apenas asumido el nuevo Gobierno, se materializó el envío al Congreso 
de un proyecto de ley de reforma tributaria, donde se recogieron prácticamente todos de los planteamientos de la campaña en esta materia ${ }^{27}$.

En lo que respecta a las modificaciones al sistema de tributación sobre base retirada, y específicamente a la eliminación del FUT, la primera versión del proyecto de ley, aprobada en poco tiempo por la Cámara de Diputados, proponía un sistema sobre base devengada, similar en sus principios al vigente hasta el 31 de diciembre de 1983, pero distinto en su mecánica de aplicación, construida sobre el controvertido concepto de renta atribuida. Adicionalmente, el proyecto establecía un incremento paulatino de la tasa del impuesto de primera categoría — desde 20 a 25 por ciento-, reduciendo la tasa marginal del impuesto global complementario y único de segunda categoría, desde 40 a 35 por ciento. Todo ello con vigencia a partir del año 2017.

El proyecto de ley fue víctima de fuertes críticas desde todos los sectores, las que fueron de carácter más técnico que político. Estas críticas se centraron básicamente en el fuerte incremento impositivo, la ausencia de medidas pro inversión que compensaran el término del beneficio de la reinversión de utilidades y en la llamada "renta atribuida", la herramienta en virtud de la cual se pasaba a cobrar impuestos a los propietarios de las empresas por las rentas devengadas por éstas. También fue blanco de ácidas críticas una retención de tasa de 10 por ciento que se les imponía a ciertas empresas.

Ya en el Senado, un ambiente crispado, sumado a las legítimas dudas que despertó el proyecto de ley en los miembros de la Comisión de Hacienda, facilitó el ambiente para que el Gobierno se abriera a ceder en sus propuestas e hizo posible la suscripción, con apoyo transversal de todos los senadores miembros de dicha comisión, de un protocolo de acuerdo que, al menos en sus postulados, y sin que a la fecha de elaboración de este trabajo se conozca la forma de implementación y el detalle de su contenido, perfecciona los principales aspectos del proyecto de ley inicialmente enviado al Congreso ${ }^{28}$.

${ }^{27}$ Proyecto de ley de reforma tributaria que modifica el sistema de tributación a la renta e introduce diversos ajustes en el sistema tributario, Boletín N. ${ }^{\circ}$ 9.290-05, de fecha 1 de abril de 2014.

${ }^{28}$ El "Protocolo de acuerdo por una reforma tributaria para un Chile más inclusivo", de fecha 8 de julio de 2014, fue suscrito por el ministro de Hacienda, don Alberto Arenas de Mesa, y los integrantes de la Comisión de Hacienda del Senado, senadores Ricardo Lagos W, Juan Antonio Coloma C., José García R, Carlos Montes C. y Andrés Zaldívar L. 
En lo que respecta a las modificaciones al FUT y a la tributación en base a renta devengada, el protocolo de acuerdo anuncia la posibilidad de que, a partir del año 2017, los contribuyentes del impuesto de primera categoría puedan optar entre dos sistemas de tributación:

i) Bajo la primera alternativa, los contribuyentes del impuesto de primera categoría deberán tributar con los gravámenes terminales - impuesto global complementario o adicional, según el caso- por las rentas atribuidas, es decir, sobre base devengada. La tasa del impuesto primera categoría (a las utilidades de las empresas) sube de 20 a 25 por ciento en cuatro años ( 21 en 2014; 22,5 en 2015; 24 en 2016; y 25 por ciento en 2017). El impuesto de primera categoría sigue siendo crédito en 100 por ciento para los socios y accionistas de la empresa al pagar el impuesto global complementario (que grava las rentas personales, con tasas de 0 a 35 por ciento) o adicional (para personas y empresas no residentes en Chile, con tasa de 35 por ciento).

ii) La segunda alternativa se define como parcialmente integrado: sube la tasa de primera categoría a 27 por ciento ${ }^{29}$. Pero en este caso, los dueños o socios pueden descontar del pago de sus impuestos sólo el 65 por ciento del impuesto de primera categoría que haya gravado los retiros o dividendos que efectúen o se les distribuyan. Bajo este sistema, la tributación de los contribuyentes del impuesto de primera categoría continuaría siendo en base percibida.

A la fecha de confección de este artículo, la discusión en el Congreso continúa respecto de algunas medidas específicas para facilitar la operación de estos sistemas paralelos y para evitar posibles focos de elusión y evasión de impuestos. Por ende, el proyecto de reforma tributaria 2014 discutido en los párrafos anteriores podría experimentar modificaciones adicionales.

${ }^{29}$ Nótese que, en caso de ser aprobado el proyecto de ley a partir del protocolo de acuerdo, la tasa del impuesto corporativo habrá aumentado casi en 63 por ciento en siete años (desde 17 por ciento hasta el 31 de diciembre de 2009 a 27 por ciento a partir del año 2017). 


\section{CONCLUSIONES}

En este trabajo analizamos el Fondo de Utilidades Tributables (FUT) desde tres perspectivas diferentes. Primero, estudiamos el contexto histórico en que surgió el FUT, los objetivos específicos para lo cual fue creado y las principales características del régimen tributario que existió previamente a su implementación. Segundo, realizamos una detallada descripción de la forma en que ha operado el FUT y de sus principales diferencias con el sistema tributario anterior y las más importantes modificaciones que ha experimentado desde su creación. Tercero, analizamos desde un punto de vista económico los incentivos que ha provisto el FUT para la reinversión de utilidades.

Nuestro análisis muestra que el FUT ha constituido una herramienta efectiva para promover el ahorro e inversión dentro de las empresas. Identificamos dos mecanismos principales de incentivos a través de los cuales el sistema tributario ha incentivado la reinversión de utilidades. Primero, argumentamos que el FUT ha permitido aumentar la disponibilidad de fondos internos para financiar inversiones en empresas con limitado acceso a los mercados de capitales. Segundo, mostramos que el FUT ha permitido suavizar el pago del impuesto global complementario en sociedades que generan flujos de utilidades volátiles en el tiempo. Adicionalmente, concluimos que este último mecanismo genera mayor justicia tributaria al permitir que los propietarios de sociedades que generan el mismo monto de utilidades en valor presente, pero en distintos momentos, tributen un monto similar de impuesto.

En este trabajo revisamos, también, el debate existente en torno al tratamiento del impuesto a la renta y proponemos algunas directrices para mejorar algunos aspectos del FUT, de manera de hacerlo aún más eficiente en su objetivo de promover el ahorro e inversión dentro de las empresas. Por ejemplo, la legislación podría considerar un sistema en base a retiros para los contribuyentes del impuesto de segunda categoría que pagan global complementario (artículo 43, n. ${ }^{\circ} 2$, de la "Ley sobre impuesto a la renta"), o incluso para los del impuesto único de segunda categoría.

Esperamos que los elementos para la discusión generados en este trabajo sirvan para sentar las bases de una discusión seria e informada de las reformas que actualmente están siendo debatidas o de las reformas que podrán venir. 


\section{REFERENCIAS BIBLIOGRÁFICAS}

Agostini, Claudio. 2011. "Una reforma eficiente y equitativa del impuesto al ingreso en Chile". Borrador para discusión, Centro de Estudios Públicos. No publicado.

—. 2013. "Una reforma eficiente y equitativa del impuesto al ingreso en Chile". Documento de trabajo 028, Escuela de Gobierno, Universidad Adolfo Ibáñez.

Arellano, José Pablo \& Vittorio Corbo, eds. 2013. Tributación para el desarrollo. Santiago de Chile: Centro de Estudios Públicos y Cieplan.

Bravo, Juan, Rodrigo Cerda \& Felipe Larraín. 2014. "Reforma tributaria: impacto económico y propuesta alternativa". Documento de trabajo 1, Centro Latinoamericano de Políticas Económicas y Sociales (Clapes UC).

Bustos, Álvaro, Eduardo Engel \& Alexander Galetovic. 2004. "Could Higher Taxes Increase the Long-Run Demand for Capital? Theory and Evidence for Chile". Journal of Development Economics 73: 675-697.

Catrilef, Luis. 2010. FUT: Fondo de Utilidades Tributables. Cuarta edición. Santiago: Legal Publishing.

Cerda, Rodrigo \& Felipe Larraín. 2005. "Inversión privada e impuestos corporativos: evidencia para Chile". Latin American Journal of Economics 42 (126): 257-28.

Cerda, Rodrigo \& Diego Saravia. 2009. "Corporate Tax, Firm Destruction and Capital Stock Accumulation: Evidence From Chilean Plants, 1979-2004”. Documento de trabajo 521, Banco Central de Chile.

Contreras, Dante \& Andrea Repetto. 2013. "Impuestos a la renta: una reforma progresiva y eficiente". En 95 propuestas para un Chile mejor. Santiago de Chile: Grupo Res Pública Chile.

Engel, Eduardo, Alexander Galetovic \& Claudio Raddatz. 1998. "Taxes and Income Distribution in Chile: Some Unpleasant Redistributive Arithmetic". Documento de trabajo de la National Bureau of Economic Research 6828.

Hsieh, Chang-Tai \& Jonathan A. Parker. 2007. "Taxes and Growth in a Financially Underdeveloped Country: Evidence from the Chilean Investment Boom”. Economia, The Journal of the Latin American and Caribbean Economic Association 8 (1).

Jorratt, Michael. 2009. "La tributación directa en Chile: equidad y desafíos". Serie Macroeconomía del desarrollo 92, Cepal.

Massone, Pedro. 1986. La reforma del impuesto a la renta en Chile. Valparaíso: Edeval.

Medina, Juan Pablo \& Rodrigo Valdés. 1998. "Flujo de caja y decisiones de inversión en Chile: evidencia de sociedades anónimas abiertas". Latin American Journal of Economics 35 (106): 301-323.

Mirrlees, James, Adam Stuart, Tim Besley, Richard Blundell, Stephen Bond, Robert Chote, Malcolm Gammie, Paul Johnson, Gareth Myles \& James Poterba, eds. 2011. Tax by Design: The Mirrlees Review. Oxford: Oxford University Press for Institute for Fiscal Studies. 
Morandé, Felipe. 2014. "Modificar el FUT, no eliminarlo". Diario La Tercera. Disponible en http://blog.latercera.com/blog/murodenegocios/entry/ modificar_el_fut_no_eliminarlo.

OCDE. 2010. "Modelo de convenio tributario sobre la renta y sobre el patrimonio". Página 193, Apartado I "Observaciones preliminares", numeral 3. http:// www.keepeek.com/Digital-Asset-Management/oecd/taxation/modelode-convenio-tributario-sobre-la-renta-y-sobre-el-patrimonio-versionabreviada_9789264184473-es\#page1.

—. 2014. "OECD Tax Database". http://www.oecd.org/tax/tax-policy/taxdatabase.htm.

Quiroz, Jorge \& Klaus Schmidt-Hebbel. 2013. "Una reforma tributaria para la eficiencia y la equidad". En 95 propuestas para un Chile mejor. Santiago de Chile: Grupo Res Pública Chile.

Valdés, Salvador. 2014. "La utilidad atribuida: una crítica económica”. Documento de trabajo 2, Centro Latinoamericano de Políticas Económicas y Sociales (Clapes UC).

Vergara, Rodrigo. 2010. "Taxation and Private Investment: Evidence for Chile". Applied Economics 42 (6): 717-725.

Zee, Howell. 1998. "Revenue, Efficiency, and Equity Aspects of Major Taxes in Chile: A Preliminary Assessment". Documento de trabajo 42, Banco Central de Chile. EP 